\title{
Dynamic causality interplay from COVID-19 pandemic to oil price, stock market, and economic policy uncertainty: evidence from oil-importing and oil-exporting countries
}

\author{
Rabeh Khalfaoui $^{1}$ (D) Sakiru Adebola Solarin ${ }^{2} \cdot$ Adel Al-Qadasi $^{3,4} \cdot$ Sami Ben Jabeur ${ }^{5}$ \\ Accepted: 15 November 2021 / Published online: 5 January 2022 \\ (c) The Author(s), under exclusive licence to Springer Science+Business Media, LLC, part of Springer Nature 2021
}

\begin{abstract}
In this study we examine the time-varying causal effect of the novel COVID-19 pandemic in the major oil-importing and oil-exporting countries on the oil price changes, stock market volatilities and the economic uncertainty using the wavelet coherence and network analysis. During the period of the pandemic, we explore such relationship by resorting to the wavelet coherence and gaussian graphical model (GGM) frameworks. Wavelet analysis enables us to measure the dynamics of the causal effect of the novel covid-19 pandemic in the time-frequency space. Regarding the findings displayed herein, we first found that the COVID-19 pandemic has a severe influence on oil prices, stock market indices, and the economic uncertainty. Second the intensity of the causality effect is stronger in the longer horizon than in the short ones, suggesting that the causality exercise continues. Our findings also provide evidence that the COVID-19 pandemic and oil price changes in oil-importing countries mirror those in oil-exporting countries and vice versa. Further, the COVID-19 pandemic has a profound immediate time-frequency effect on the US, Japanese, South Korean, Indian, and Canadian economic uncertainties. A better understanding of oil and stock market prices in the oil-importing and oil-exporting countries is vital for investors and policymakers, specially
\end{abstract}

$\triangle$ Rabeh Khalfaoui

rabeh.khalfaoui@gmail.com

Sakiru Adebola Solarin

sakirusolarin@gmail.com

Adel Al-Qadasi

alqadasi@su.edu.sa

Sami Ben Jabeur

sbenjabeur@gmail.com

1 Laboratoire de recherche en Économie et Gestion (LR18ES27), FSEG, Sfax, Tunisia

2 School of Economics, University of Notthingham Malaysia, Jalan Broga, 43500 Semenyih, Selangor, Malaysia

3 College of Science and Humanities in Al-Dawadmi, Shaqra University, Al-Dawadmi, Shaqra, Saudi Arabia

4 The Hodeidah University, Hodeidah, Yemen

5 Institute of Sustainable Business and Organizations, Confluence: Sciences et Humanités - UCLY, ESDES, Lyon, France 
since the novel unprecedented COVID-19 crisis has been recognized among the most serious ever happened. Thus, the findings suggest that the authorities should strongly take efficient actions to minimize risk.

Keywords COVID-19 - Oil price · Stocks · Economic uncertainty · Wavelet analysis . Gaussian graphical model $\cdot$ Value-at-Risk

JEL Classification C58 · G15 · Q4

\section{Introduction}

The novel coronavirus disease 2019 (COVID-19), which was first reported in Wuhan, China is one of the worst pandemics that the world has ever witnessed as it has generated unparalleled public health crises; and severe economic and social setbacks. More than eight million people have contracted the disease and about 460 thousand people have died of the disease, worldwide (World Health Organization, 2020). The global economy is expected to shrink by almost three percent in 2020, much greater than the decline experienced during the global financial crisis of 2008-2009 (International Monetary Fund, 2020). Several variables have experienced tremendous changes since the inception of the COVID-19 pandemic. For instance, oil prices have mostly decreased since the inception of the COVID-19 pandemic. Oil prices declined by around $70 \%$ in the first quarter of 2020; and the global oil demand is expected to decline by around 10 percent in 2020, more than double the next biggest drop in 1980 (World Bank, 2020). Unlike the COVID-19 pandemic that has a negative in all countries, the impact of the decline in oil price in a country depends on whether it is an oil-importing or oil-exporting one (World Bank, 2020).

Uncertainty has been rising during the COVID-19 pandemic. For instance, the news-based global economic policy uncertainty index of Baker et al. (2016) (based on purchasing power parity-adjusted gross domestic product or GDP) increased from 234 in January 2020 to 298 in September 2020. The sources of the uncertainty of the pandemic are multifaceted including the infectiousness, pervasiveness and deadliness of the disease. Uncertainty also arises from the extent to which the pandemic- induce (and unforeseen) changes in consumer spending will last. It has been suggested that economic policy uncertainty inhibits economic growth, investment and hiring, and negatively affect policy-sensitive sectors like healthcare, defense, finance and construction (Baker et al., 2020a).

COVID-19 pandemic has negatively affected financial markets in general and stock markets in particular. On 28 February 2020, global stock markets experienced in the biggest single-week decreases since the global financial crisis in 2008. In March 2020, the value of the equity market in the globe fell by $30 \%$ (Baker et al., 2020b). The negative impact of COVID-19 pandemic on the stock market is more severe than the past infectious disease pandemic, including the 1918 Spanish influenza pandemic, which resulted in the death of about 2.0 percent of the global population then (which killed an estimated 2.0 percent of the world's population (International Monetary Fund, 2020). Although stock markets across the world have recovered in the later part of the year, the second and third waves of the virus have caused volatility in several countries.

The importance of studying the relationship between COVID-19 pandemic, oil price, stock market, and economic policy uncertainty can hardly be overemphasized. A comprehensive understanding of the relationship in these series can provide insights for the appropriate 
policy response in the macroeconomic environment. Hence, few papers have examined the interplay among these series (Altig et al., 2020; Ashraf, 2020; Brown \& Rocha, 2020; Goodell, 2020; Oldekop et al., 2020). However, the bulk of these has predominantly focused on developed and oil-importing countries. The status of oil in an economy partly determines policy implications. For instance, lower prices are generally bad for oil-exporting countries because the oil price fall is a commodity terms-of-trade innovation that impacts the economy via a decline in export receipts and government revenues. Lower prices are good for oil importers because they can trigger lower costs of production as well as low inflation in these countries. Therefore, one motivation to still conduct an empirical analysis of the COVID-19 pandemic and macroeconomic variables is that the results of the existing studies are generally only relevant for developed and oil-importing countries.

The aim of this paper is to extend the existing literature on COVID-19 pandemic. The first contribution of this study is to examine the causal effects of COVID-19 pandemic on oil prices, stock market returns, and economic policy uncertainty in leading oil exporting (Saudi Arabia, Iraq, Russia, UAE and Canada) and oil-importing countries (including China, US, India, Japan and South Korea). This is an area that requires further exploration. We were motivated to carry out this study because there is a strong need for a novel approach, particularly with regard to exploring potential dynamic relationships between variables. Compared to other econometric methods, the use of wavelet tools, including the wavelet coherence and the phase relation analyses, contributes better insight into the link between the COVID-19 pandemic and the stock market, oil prices, and economic uncertainty in both oil-importing and oil-exporting countries over time and frequency. Furthermore, wavelet analysis permits an understanding of the lead-lag relationship between the variables. This framework allows for quantifying the intensity of the dependence between the COVID-19 pandemic and the other variables of interest and also makes it possible to distinguish between the short- and long-term causal effects of the COVID-19 crisis on the stock market, oil prices, and economic uncertainty in both oil-importing and oil-exporting countries. This study is set out to explore the complex relationships between variables under the COVID-19 pandemic through Gaussian graphical models, which has been widely adopted by the scientific community in natural sciences, social sciences and psychological (Bhushan et al., 2019; Epskamp et al., 2018). The Gaussian graphical model (GGM) will be used in the first stage to assess the association between the COVID-19 pandemic, oil prices, stock market prices, and economic policy uncertainty. The application of graphical models, which is new in the literature, allows for the quantification and visualization of significant connections within a network. In this study, we employed GGM analysis to examine the strength of the relationships between the different variables of concern. In this network analysis, however, the variables (COVID-19, oil prices, stock market prices, economic policy uncertainty) are presented as a set of nodes, and a significant association is depicted by an edge linking them. We hope that by using the GGM network, we can further discover the intensity of the dependence of the COVID-19 pandemic and other variables. To the best of our knowledge, this GGM analysis is the first to focus on the novel COVID-19 pandemic in connection with oil prices, stock market prices, and economic policy uncertainty in oil-importing and oil-exporting countries.

Based on this framework, we are not aware of any research that has been carried out on these relationships. This method gives us a valuable technique for evaluating an expanded range of stock markets and drawing inferences by visual analysis. The second contribution of this study is the use of a wavelet coherence analysis, which can afford a perfect alternative to scrutinize the causality directions from covid-19 crisis towards oil price spreads. Moreover, wavelet methods capture the nonlinearity behavior under the COVID-19 spread (Sharif et al., 2020) and represent an invaluable tool in small datasets compared to traditional econometrics 
methods. Our findings show that the covid-19 pandemic has a greater influence on the oil price changes, stock market volatilities, and the economic policy uncertainty spreads, and provide new influential strategy and practical consequences for policy makers.

The assessment of the dependence between economic and financial changes has been the contribution of several operations research scholars in recent years (Bernard et al., 2018; Khalilpourazari \& Hashemi Doulabi, 2021; Kılıç \& Uğur, 2018; Tzagkarakis \& Maurer, 2020). Operations research scholars have examined economic and financial systems as complex harmonized models. Therefore, from both an economic thinking and operations research perspective, we refer to the field of operations research in order to explore the dynamics of the causal effect of the COVID-19 pandemic on oil prices, stock market prices, and economic policy uncertainty in oil-importing and oil-exporting countries.

We organized the rest of this study as follows: Sect. 2 contains literature survey of the study while a theoretical description of the method is presented in Sect. 3. The data description and the network analysis are presented in Sect. 4. The discussion of the wavelet coherence findings appears in Sect. 5. We conclude in Sect. 6.

\section{Related literature}

An enormous amount of work has been carried out on the dependence structure among financial markets especially in crisis period. Rafiq et al. (2009) investigated the effects of the fluctuations of oil prices in Thailand over the period from 1993Q1 to 2006Q4 by using the vector auto-regression (VAR) model. They found that the effect of oil price fluctuations is conveyed to the budget deficit for the post-crisis era. Zhang et al. (2009) examined the impact of extreme events in crude oil markets. The findings show that empirical mode decomposition provides a viable approach to calculating the effect of severe events on fluctuations in crude oil prices. Bhar \& Malliaris (2011) revealed that the oil price collapse happened in the midst of the financial crisis and more precisely in the second half of 2008. Wen et al. (2012) applied time-varying copulas to examine if there was a contagion impact between energy and capital markets during the Subprime crisis. The results show Evidence was identified for a substantial rise in dependency between crude oil and stock markets following the collapse of Lehman Brothers. Reboredo \& Rivera-Castro (2013) analyzed the relationship between oil prices and US dollar exchange rates using the Wavelet Multi-Resolution approach. The authors found that oil and exchange rates in the pre-crisis era were not dependent, but we found evidence of contagion and negative dependency following the onset of a crisis. Using wavelet multiresolution analysis Reboredo \& Rivera-Castro (2014) suggested that shifts in oil prices had little impact on stock market returns at any aggregate or sectoral level during the pre-crisis era. Based on wavelet analysis, Tiwari et al. (2019) investigated the relationship of market volatility and economic policy uncertainty. They found that the relationship between the two variables is time-variant and not positive at all the times. Moreover, the same methodology has been used by Tiwari et al. (2018) to examine the linkage between price indices of oil and 21 agricultural commodities. The findings show a high degree of co-movement at long-run horizon between the price indices of oil and coal, cotton, fishmeal, maize, rice, rubber, and wheat. More recently, Khalfaoui et al. (2021) used the wavelet coherence and quantile crossspectral analyses to explore the relationship between the oil market and the major precious metals (e.g., gold, silver platinum, palladium) and the base metal copper. The authors revealed that gold and platinum are highly connected with oil and influence oil prices, especially during turmoil of global markets. Tsai (2015) explored how US stock returns respond differently 
to oil price shocks before, during and after the financial crisis. They found that major firms were most impacted and adversely affected by the oil price shocks before the crisis. On the other hand, their findings suggest that in the case of medium-sized companies, the oil price impact on the post-financial crisis era has been positively exacerbated. Yaya et al. (2016) analyzed the sustainability of instability and the emergence of spillovers between the oil and gold markets using regular historical data from 1986 to 2015, separated into phases before and after the global crisis. The findings reveal that the uncertainty of the gold price was smaller than that of the oil market before and during the crisis era. Before the crisis time, the return spillover impact was bidirectional, while it was unidirectional from gold to the post-crisis oil sector. Mei-Se et al. (2018) used the recursive cointegration to examine the linkage among three metals' prices, oil price, and the US dollar exchange rate. The authors concluded that there has been a substantial and clear correlation between the price of gold and other variables for most of the time since 1995, and that the European sovereign debt crisis has resulted in a stronger relation between 2010 and 2012.

In recent years, the dependence of the economic policy uncertainty (EPU) on crude oil prices has drawn more attention in the literature. For one thing, the EPU is a significant engine of real economic operations, and may influence the output plans or expenditure decisions of firms and consumers, and thus affect the demand for crude oil and investment, as well as the volatility of oil prices (Zhang \& Yan, 2020). Hailemariam et al. (2019) investigated the linkage between oil prices and economic policy uncertainties in the G7 countries. They found that the impact of oil prices on economic policy volatility is time-varying. In addition, the findings indicate that the approximate time-varying feature of the oil price was negative in the years in which the rise in oil prices was guided by an increase in global aggregate demand. Wei (2019) discussed the impact of oil price shocks and global policy fluctuations in Chinese markets. The results notice that oil supply and economic policy uncertainty shocks can significantly reduce China's real exports, whereas oil aggregate demand and oil-specific market shocks can significantly increase real exports. According to Sun et al. (2020) that the relationship between economic policy uncertainties and short-term oil prices is small but steadily rises over the longer term, particularly when major historical political or financial events have taken place. Wu et al. (2021) examined the effect of economic policy uncertainty on the returns of four cryptocurrencies based on the recursive evolving window approach. The authors found that the Twitter-based economic policy uncertainty measures primarily positively affect the returns of the related cryptocurrencies during the COVID-19 pandemic period. Mokni et al. (2020) used time-varying parameter vector autoregression (TVP-VAR) to examine the relationship between oil price shocks and the gold price. The findings show a major impact on economic policy uncertainty on the relation between oil shocks and the gold market in both the static and the regime-switching frameworks. Tiwari et al. (2021) employed time-varying Markov-switching copula models to examine the dependence structure and dynamics between artificial intelligence and carbon prices in the era of the fourth industrial revolution during the COVID-19 pandemic. The findings indicate a negative dependence structure for the return series between artificial intelligence and carbon prices.

Mokni (2020) examined the relationship between oil prices and equity markets in major oil-exporting and oil-importing countries. The author found that the relationship between oil and equity markets is asymmetrical, with stock markets reacting more strongly to negative oil price shifts than positive ones. Similarly, from January 2005 to December 2014, Dimitriadis and Katrakilidis (2020) investigated the complex interactions of ethanol, crude oil, and corn market prices in the United States. Alamgir \& Amin (2021) used a nonlinear autoregressive distributed lag model to examine the interactive relationship between oil prices and the stock market in four South Asian countries from 1997 to 2018. Their findings show a positive 
relationship between the global oil price and the stock market index and, further, that the stock market index's reaction to positive and negative oil price shocks is asymmetric. Moreover, Sui et al. (2021) explored the influence of three forms of epidemics on crude oil prices using data from around the world for the years 1976 to 2018. The authors found that disease intensity is a significant force affecting oil markets and that the influence extends from the bond market as a consequence of speculative investor behavior.

Studies on the effect of COVID-19 on economic and management become an active research area (Altig et al., 2020; Ashraf, 2020; Brown \& Rocha, 2020; Gharib et al., 2020; Goodell, 2020; Oldekop et al., 2020). For example, Gharib et al. (2020) examined the causal relationship between crude oil and gold prices from January 4, 2010, to May 4, 2020. The authors found a bilateral contagion of oil and gold bubbles during the recent COVID-19 outbreak. Sharif et al. (2020) analyzed the link between the recent spread of COVID-19, the shock of oil price volatility, the stock market, geopolitical risk and economic policy uncertainty in the US within a time-frequency framework. The findings show that COVID19 has a significantly higher impact on geopolitical risk than on US economic uncertainty. Over the short and long term, the COVID-19 risk is perceived differently and can be viewed as an economic crisis. Salisu et al. (2020) investigated the behavior of oil-stock nexus during COVID-19 crisis. Using panel Vector Autoregressive model, the results indicate that during the pandemic, both oil and stock markets may experience greater initial and prolonged impacts of own and cross shocks than the period before it. Our study extends previous research on the impact of Covid-19 in the major oil-importing and oil-exporting countries including economic policy uncertainty. In fact, earlier studies have investigated the dynamic dependence between EPU and stock markets (Choi, 2020; Le et al., 2020; Sharif et al., 2020). Therefore, our current study aims to explain these during the COVID-19 outbreak, while considering a large panel of data, including importing and oil-exporting countries.

Zhang \& Hamori (2021) analyzed the return and volatility spillover of crude oil and the stock market during the COVID-19 pandemic in 2020. Their results indicate that COVID19 creates extraordinary levels of damage, such as falling oil prices and on four occasions activating the US stock market circuit breaker, causing investors to lose a lot of money in a brief amount of time. Furthermore, the influence of COVID-19 on the instability of the oil and bond markets was greater than that of the 2008 global financial crisis. Vo \& Hung (2021) investigated the spillover effects and time-frequency connectedness between crude oil prices, gold assets, and the S\&P 500. Their results shed light on a comparison to the time before COVID-19, and return transmissions are more evident during the COVID-19 crisis. Yousfi et al. (2021) compared the effects of the first and second waves of the current COVID-19 pandemic on the US financial market and its volatility. The authors revealed that the dynamic correlation method supports the existence of volatility spillovers between the two stock markets, notably during COVID-19's rapid spread in the United States. Second, an examination of an influential association with the news revealed that shocks to the US and Chinese markets have asymmetric effects on their correlations.

\section{The methodology}

\subsection{The wavelet}

A wavelet is defined as a function localized in the time and frequency domains. In other words, a wavelet is a "small wave packet" that oscillates in both time and frequency over a 
time position $a$ and scale $b$. However, it is limited to a given time period. A time series $x(t)$ can be transformed using the so-called mother wavelet $\psi(t)$, which is a function of time $a$ and scale $b$. However, this function can be transformed and dilated using the parameters $a$ and $b$, respectively. A wavelet can be expressed as follows:

$$
\psi_{a, b}(t)=\frac{1}{\sqrt{b}} \psi\left(\frac{t-a}{b}\right), a, b \in \mathbb{R}, b \neq 0
$$

where $\psi(t)$ is the mother wavelet with zero mean: $\int_{-\infty}^{+\infty} \psi(t) d t=0$; finite energy: $\int_{-\infty}^{+\infty} \psi^{2}(t) d t=1$; and also satisfying the so-called admissibility condition: $0<C_{\psi}=$ $\int_{0}^{+\infty} \frac{|\psi(f)|^{2}}{|f|} d f<+\infty$. The Fourier frequency is denoted by $f$, and $\psi(f)$ is the Fourier transform function.

\subsection{The continuous wavelet transform}

Let $x(t) \in L^{2}(\mathbb{R})$ be a time series; the continuous wavelet transform (CWT) of $x(t)$ with regard to the mother wavelet $\psi$ is given by the following:

$$
W_{x}(a, b)=\frac{1}{\sqrt{b}} \int_{-\infty}^{+\infty} x(t) \psi^{*}\left(\frac{t-a}{b}\right) d t
$$

where $*$ refers to the complex conjugation. The CWT of $x(t)$ refers to the portion of the scale $b$ at several time positions $a$, and $1 / \sqrt{b}$ is the normalization factor that guarantees the unit variance of $\psi:\left\|\psi_{a, b}\right\|^{2}=1$.

One benefit of the CWT is its ability to reconstruct the time series $x(t)$ without lowering energy information. In fact, $x(t)$ can be reconstructed by inverting the CWT using the following formula:

$$
x(t)=\frac{1}{C_{\psi}} \int_{0}^{+\infty}\left[\int_{-\infty}^{+\infty} W_{x}(a, b) \psi_{a, b}(t) d a\right] \frac{d b}{b^{2}}, b \neq 0
$$

Therefore, one can say that the CWT preserves the energy of the time series $x(t)$, which is denoted by $\|x\|^{2}$, where

$$
\|x\|^{2}=\int_{-\infty}^{+\infty}|x(t)|^{2} d t=\frac{1}{C_{\psi}} \int_{-\infty}^{+\infty}\left[\left|W_{x}(a, b)\right|^{2} d a\right] \frac{d b}{b^{2}}
$$

There are different mother wavelets used in the literature, including Daubechies, symlet, coiflet, Morlet, Shannon, Mexican hat, and more. Herein, we use the complex Morlet wavelet developed by Goupillaud et al. (1984). It is expressed as follows:

$$
\psi_{\varsigma}(t)=\pi^{-1 / 4}\left(e^{i \varsigma t}-e^{\frac{-\varsigma^{2}}{2}}\right) e^{\frac{-t^{2}}{2}}
$$

Equation (5) can be reformulated after certain admissibility circumstances for the Morlet wavelet to obtain the simplified formula

$$
\psi_{\varsigma}(t)=\pi^{-1 / 4} e^{i \varsigma t} e^{-t^{2} / 2}
$$

where $t$ indicates the time, $\varsigma$ dimensionless the wavelet frequency, and the term $\pi^{-1 / 4}$ denotes the weighting factor ensuring the same energy for the wavelets at various scales. 


\subsection{The wavelet power and cross-wavelet power spectra}

The wavelet power spectrum is called from time to time the scalogram or the wavelet periodogram. It presents the local variance of $x(t)$ over different frequencies. Following Torrence \& Compo (1998) and Aguiar-Conraria et al. (2008), the wavelet power spectrum displays the changing behavior of the variance of $x(t)$ at a point of time and scale. It is expressed by the formula $W P S_{x}(a, b)=\left|W_{x}(a, b)\right|^{2}$.

To examine the joint behavior of oil prices and the COVID-19 crisis in time and frequency, we have to specify a cross-wavelet transform to identify the common power between them. It is a measure that determines the local covariance between two time series $x(t)$ and covid( $t)$, for instance, where $x(t)=\operatorname{oil}(t)$, stock $(t), E P U(t)$, with the continuous wavelet transforms $W_{x}(a, b)$ and $W_{\text {covid }}(a, b)$. It is given as follows:

$$
W_{x, \text { covid }}(a, b)=W_{x}(a, b) \bar{W}_{\text {covid }}(a, b)
$$

where $a$ and $b$ are the location and scaling operators, respectively, and the upper bar indicates complex conjugation. The expression of XWS is $\left|W_{x, \text { covid }}(a, b)\right|$.

The XWS quantifies the similarity of power between $x(t)$ and covid(t). The theoretical distribution of XWS for $x(t)$ and covid(t) is defined by Torrence \& Compo (1998) with background power $P_{f}^{x}$ and $P_{f}^{\text {covid }}$, as follows:

$$
G\left(\frac{\left|W_{x, t}(S) W_{\text {covid }, t}^{*}(S)\right|}{\sigma_{x} \sigma_{\text {covid }}}<p\right)=\frac{Z_{v}(p)}{v} \sqrt{P_{f}^{x} P_{f}^{\text {covid }}}
$$

where $S$ refers to the smoothing parameter, and $Z_{v}(p)$ denotes the confidence level associated with the probability $p$ for a probability density function determined by the square root of the product of two $\chi^{2}$ distributions (Torrence \& Compo, 1998).

\subsection{The wavelet coherence and phase difference}

The wavelet coherence method is used herein to capture the dynamic dependence between oil price, stock market prices, and economic policy uncertainty in oil-exporting and oilimporting countries by considering the influence of COVID-19 pandemic in both the time and frequency domains. This approach is defined by Aguiar-Conraria et al. (2008) as the percentage of the cross-wavelet power spectrum (XWS) to the spectrum product of each time series.

Following (Aguiar-Conraria et al., 2008; Grinsted et al., 2004) the wavelet coherence is the proportion of XWS to the spectrum product of each individual series $\mathrm{x}(\mathrm{t})$ and $\operatorname{covid}(\mathrm{t})$ is given by the following formula:

$$
R_{x, \text { covid }}=\frac{\left|S\left(s^{-1} W_{x, \text { covid }}(a, b)\right)\right|^{2}}{S\left(s^{-1}\left|W_{x}(a, b)\right|^{2}\right) S\left(s^{-1}\left|W_{\text {covid }}(a, b)\right|^{2}\right)}
$$

where $\mathrm{S}$ refers a smoothing operator for both time and frequency. The values of $R_{x \text {,covid }}$ ranges between 0 and 1 . The greater the values of $R_{x \text {,covid }}$, the greater the dependence between oil and COVID-19.

As the wavelet coherence coefficients are all positive (ranging between zero and one) due to the square operator in $R_{x \text {,covid, }}$, we cannot understand the sign of the direction for the causality interplay between the two time series $x(t)$ and covid $(t)$. However, negative and 
Scheme 1. Schematic illustration of the phase difference

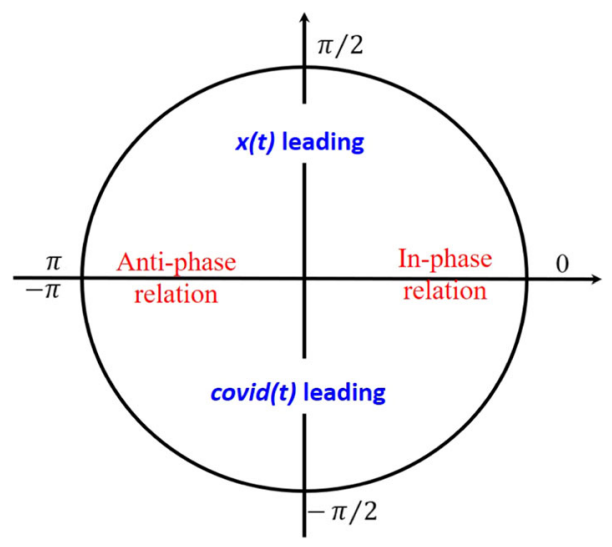

positive correlations are not distinguished using the wavelet coherence coefficients. We use the so-called "phase difference" or "phase relation", as it enables us to manage the positive and negative correlations as well as the lead-lag relationships between $x(t)$ and covid( $t)$ time

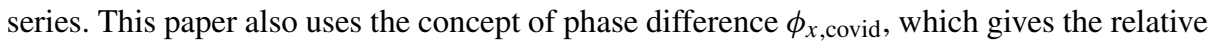
position of $x(t)$ and covid $(t)$. The phase difference is given by the following formula:

$$
\phi_{x, \text { covid }}=\tan ^{-1}\left(\frac{\operatorname{Im}\left\{S\left(s^{-1} W_{x, \text { covid }}(a, b)\right)\right\}}{\operatorname{Re}\left\{S\left(s^{-1} W_{x, \text { covid }}(a, b)\right)\right\}}\right)
$$

where $\phi_{x \text {,covid }} \in(-\pi, \pi)$, Im and Rm refer to imaginary and real part of the cross-wavelet transform, respectively.

The phase relation structure is given in Scheme 1. This plot depicts the phase difference significance between $x(t)$ and covid $(t)$. A phase difference coefficient equal to zero indicates that $x(t)$ and covid $(t)$ time series move together at the specified frequency. While, a phase difference of $\pi$ or $-\pi$ represents an anti-phase relation.

For more details about the wavelet method employed in our study please refer to (AguiarConraria \& Soares, 2014; Aguiar-Conraria et al., 2008, 2012; Grinsted et al., 2004).

\section{Preliminary and network analysis}

\subsection{Preliminary analysis}

To carry out our analysis, we collect daily data for COVID-19 confirmed cases in the major oilimporting and oil-exporting countries, daily oil (WTI) sport prices, daily stock market indices, and economic policy uncertainty. The data for oil is sourced from EIA (https://www.eia.gov/), the data for COVID-19 is sourced from (https://data.humdata.org/), the data for stock market index is sourced from (https://www.investing.com/), and the data for the economic policy uncertainty is sourced from (http://www.policyuncertainty.com) as developed by Baker et al. (2016). The starting dates for each case are shown in Table 1, while the ending date for all cases is the 14th of September 2020, except that for the economic policy uncertainty variables are 31st of August 2020 based on the availability of the data. In the case of KSA, and due to the differences of holidays in the Saudi stock market and other markets, we replaced the missing data by the mean of the available values (Brown \& Kros, 2003; Liu et al., 1997). 


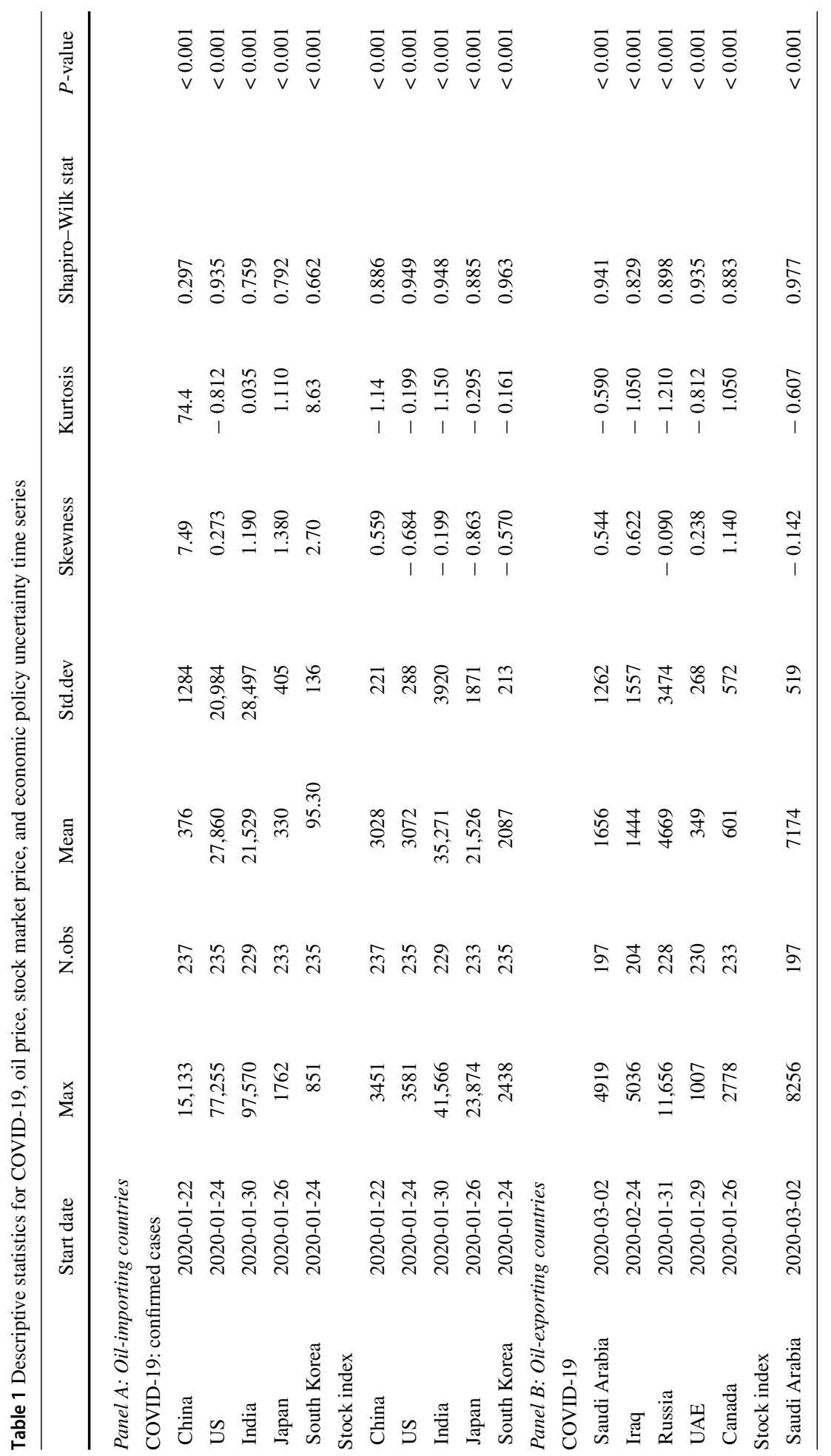




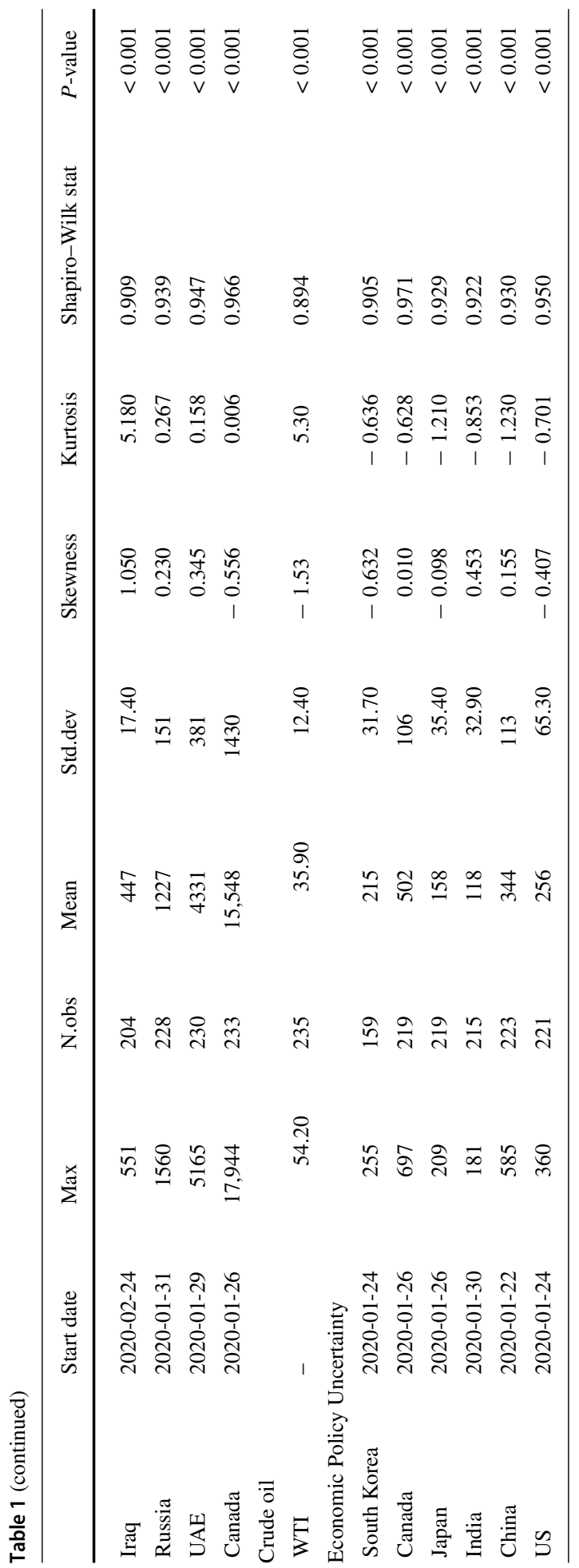


Oil Exporting Countries: COVID-19, confirmed cases
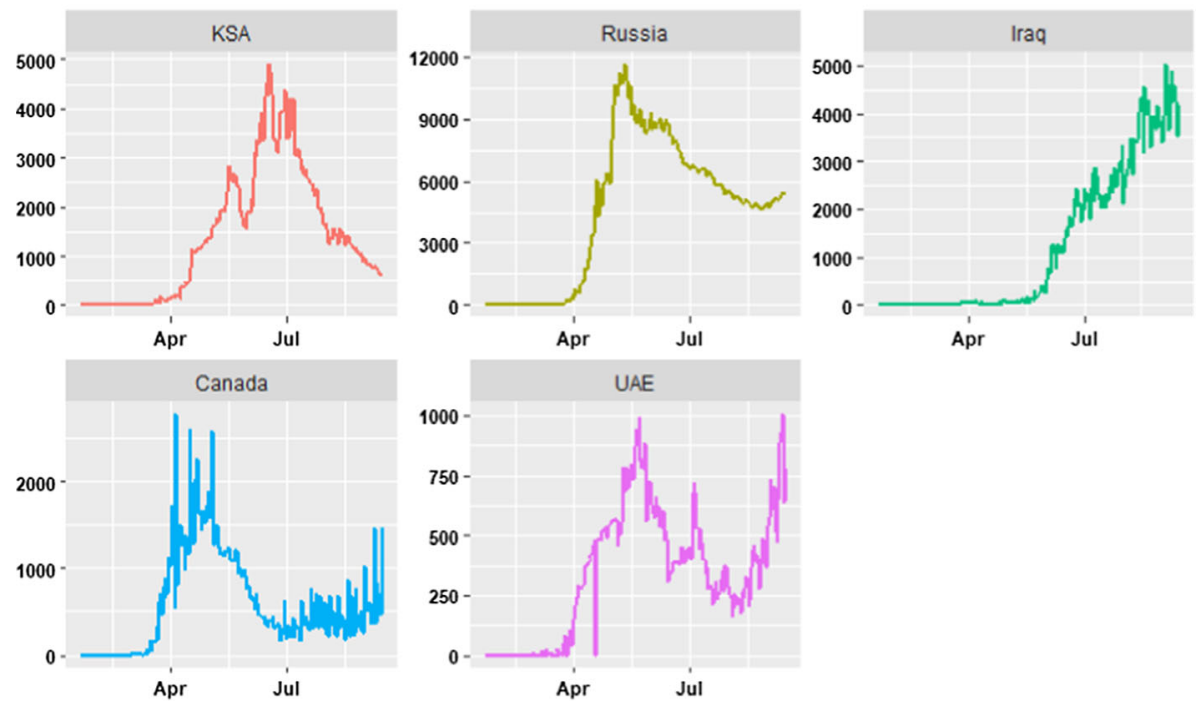

Fig. 1 COVID-19 evolution dynamics in oil-exporting countries

An overview of the descriptive statistics for the employed time series is reported in Table 1. It is clearly noticeable that all the variables have skewed and leptokurtic distributions, as demonstrated by the values of the skewness and excess kurtosis. The Shapiro-Wilk statistical test (Shapiro \& Wilk, 1965) strongly reject the normality property for the time series, which indicates that the unconditional distribution of all the variables are non-normal.

Figures 1, 2, 3 portrays the time series for the COVID-19 outbreak in the oil-exporting, oil-importing countries, and the oil price, respectively. Whereas, the dynamic changes for the stock market indices and the economic policy uncertainty are graphed in Figs. 33, 34, respectively. From Figs. 1, 2, 3, clearly the overall changes present two-phase patterns in the series for all oil-exporting countries and for the cases of the US and India as oil-importing countries: (i) the exponential model, in which the number of COVID-19 confirmed cases increases exponentially (ii) the quite linear model, in which the number of COVID-19 confirmed cases decreases slowly linear. As can be seen in Fig. 3, the oil price started decreasing as from the beginning of the COVID-19 crisis. The dynamic of the oil price depicts a rough downfall on 20th April 2020 corresponding to 25,899 confirmed cases in US. Figures 4, 5, 6 Show a first look for the standard connectedness between COVID-19, oil price, stock market prices, and economic policy uncertainty. Figures Figs. 35 and 36 in the "Appendix A", depict the original data of the time series for the stock market indices and economic policy uncertainties.

\subsection{Network analysis}

In the natural sciences, social sciences, and economics, Gaussian graphical models (GGM) are used to model statistical interactions between variables of interest in the form of a graph. A GGM collects conditional relations that are normally visualized to infer the underlying 


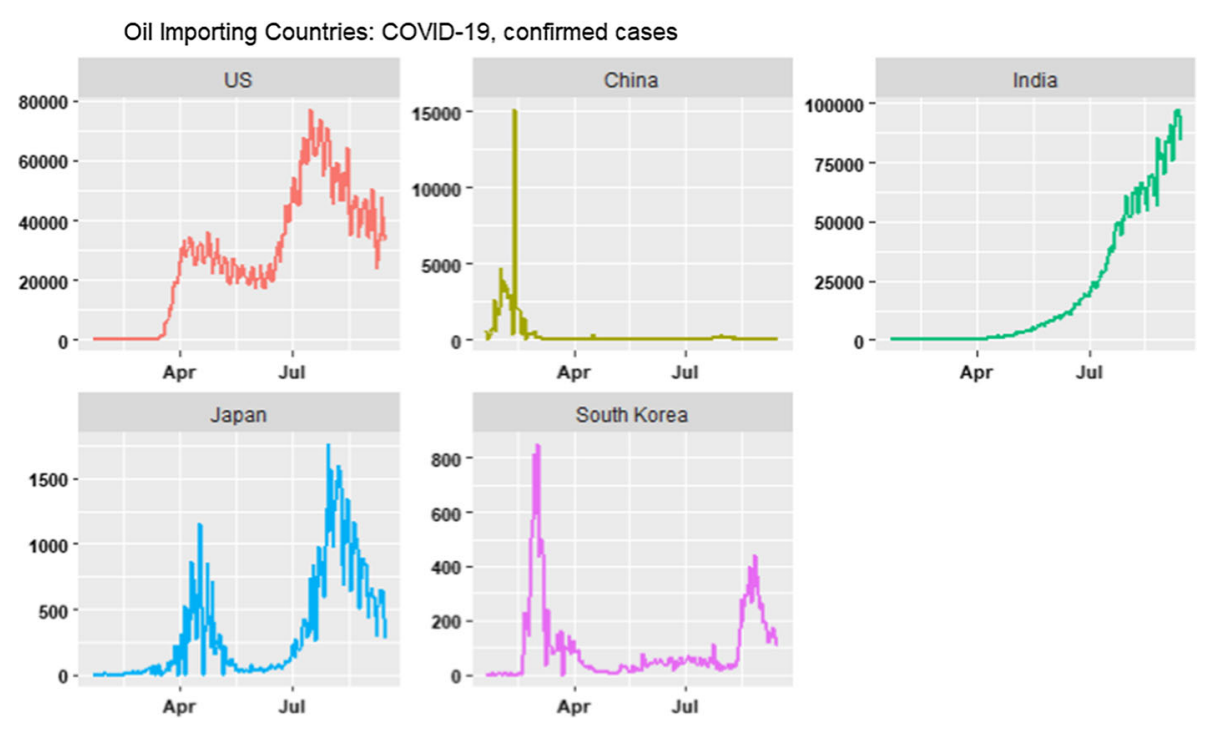

Fig. 2 COVID-19 evolution dynamics in oil-importing countries

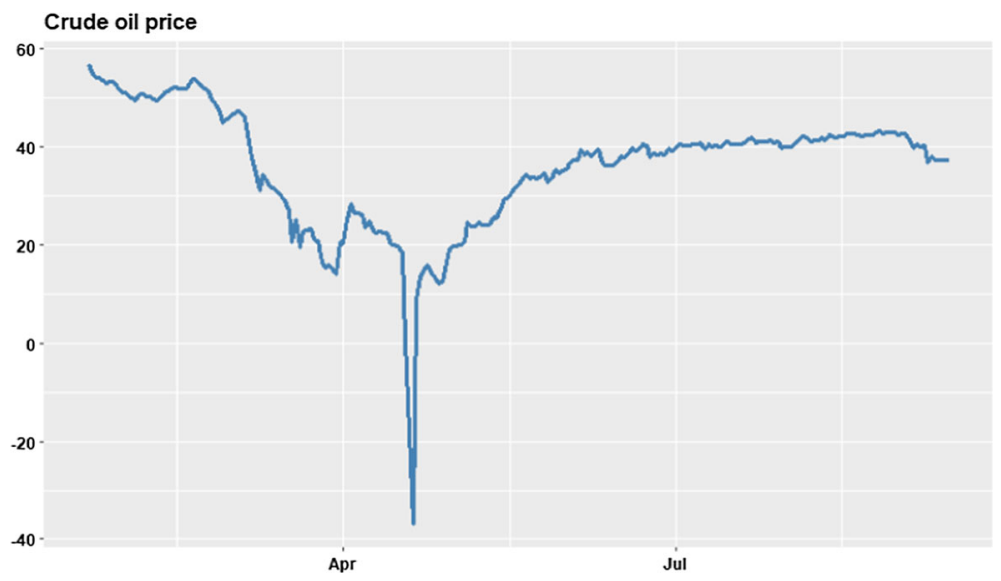

Fig. 3 Crude oil (WTI) price evolution during the COVID-19 pandemic

dependency structure for multivariate normal data (Williams \& Mulder, 2020). More precisely, a GGM consists of a collection of items or variables represented by circles and a set of lines that depict the relationships between the items or variables. According to Malioutov et al. (2006), a GGM model is defined by an undirected diagram $\mathrm{D}=(\mathrm{U}, \mathrm{F})$, where $\mathrm{U}$ is the set of nodes and $\mathrm{F}$ is the set of edges and a collection of jointly Gaussian random features $X=\left(X_{i}, i \in U\right)$. The probability density is calculated as follows:

$$
P(X)=\exp \left\{-\frac{1}{2} X^{h} K X+t^{h} X\right\}
$$




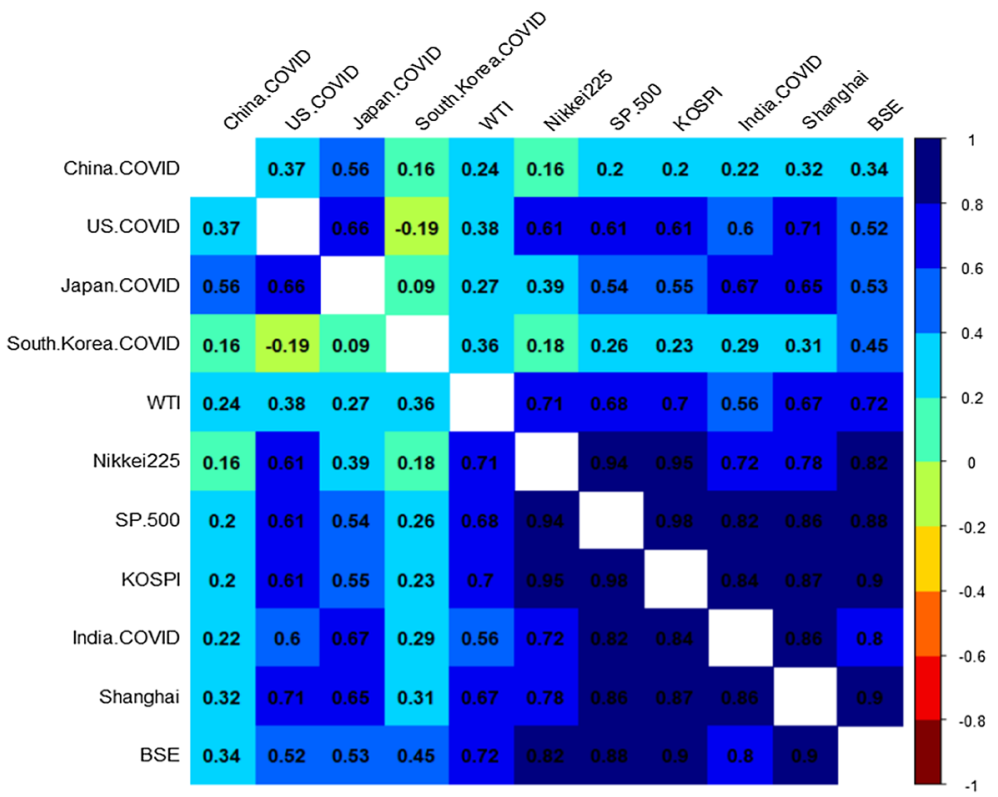

Fig. 4 Pearson correlation matrix for the COVID-19 outbreak, crude oil (WTI), and stock market indices in the oil-importing countries. Note: The color bar denotes the magnitude of the intensity for the correlation between variables

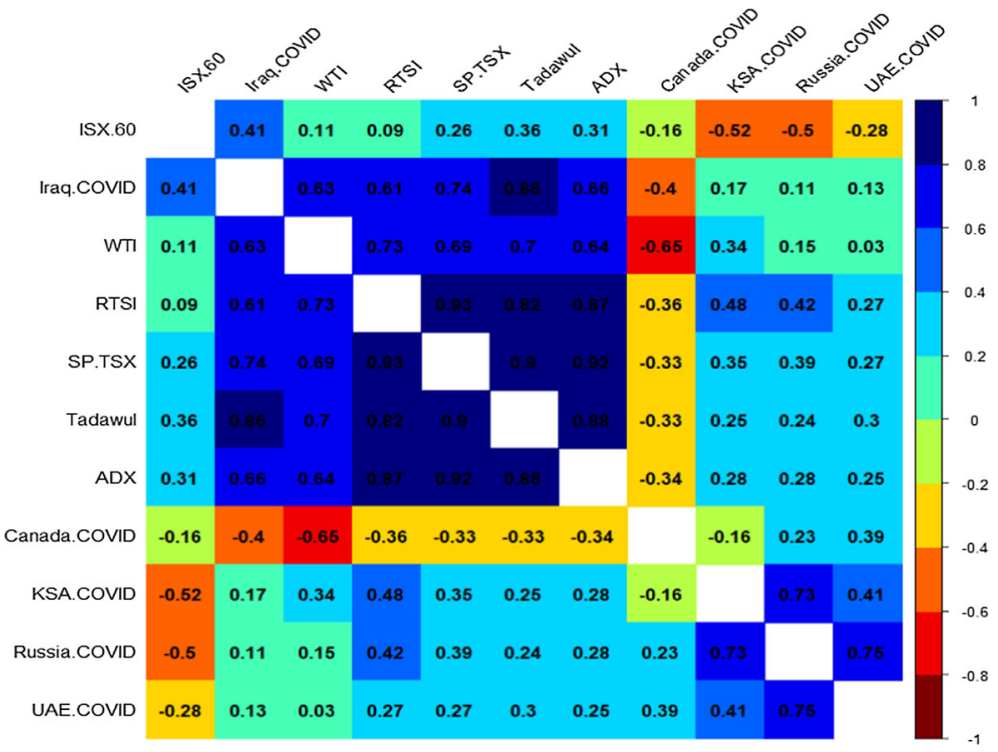

Fig. 5 Pearson correlation matrix for the COVID-19 outbreak, crude oil (WTI), and stock market indices in the oil-exporting countries. Note: see note in Fig. 4 


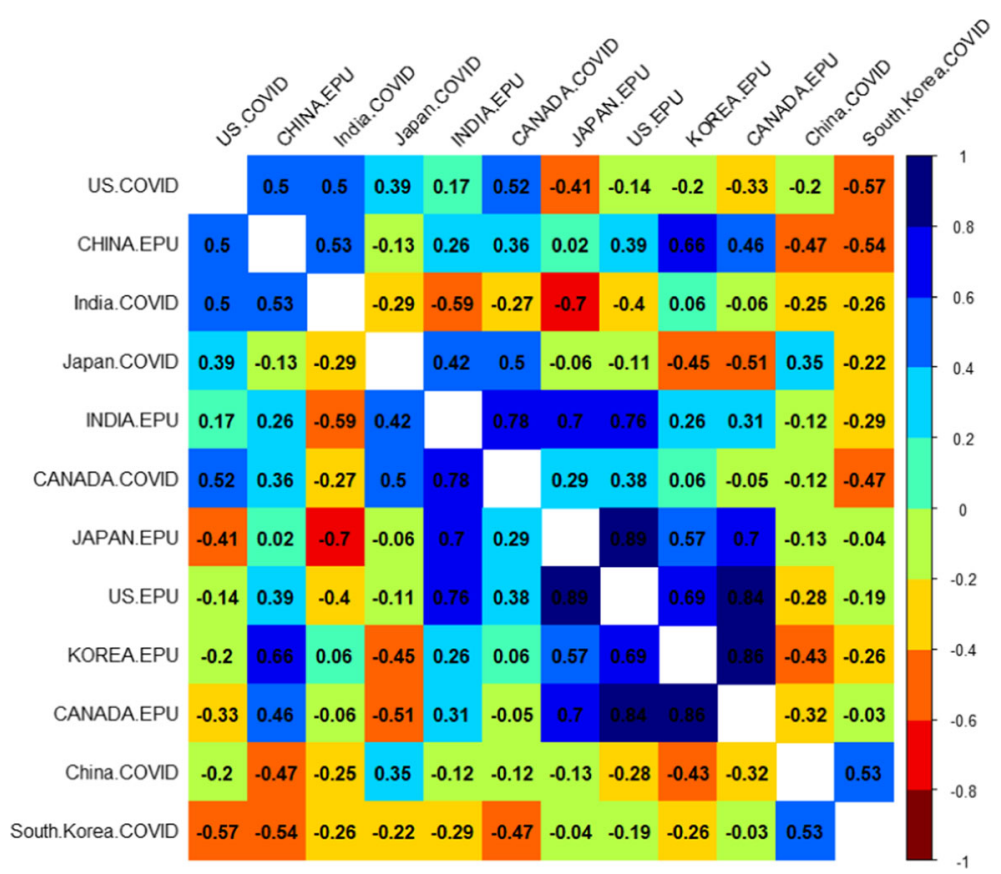

Fig. 6 Pearson correlation matrix for the COVID-19 outbreak and the economic policy uncertainty. Note: see note in Fig. 4

where $\mathrm{K}$ is a positive definite symmetric matrix, and $\mathrm{t}$ is the potential vector. In terms of mean and covariance, they are related to normal Gaussian parameterization.

The partial correlation coefficient between features $X_{i}$ and $X_{j}$ determines their conditional correlation, while the other variables' values are taken into account. These are calculated by normalizing the information matrix $(\mathrm{K})$. The partial correlation is described as follows:

$$
r_{i j}=-\frac{K_{i j}}{\sqrt{K_{i i} K_{j j}}}
$$

For Gaussian models, the node and edge functions can be expressed as follows:

$$
\omega_{i}\left(X_{i}\right)=\exp \left\{-\frac{1}{2} K_{i i} X_{i}^{2} t_{i} X_{i}\right\} \quad \text { and } \omega_{i j}\left(X_{i}, X_{j}\right)=\exp \left\{-\frac{1}{2}\left[X_{i} X_{j}\right] K_{i j}\left[\begin{array}{c}
X_{i} \\
X_{j}
\end{array}\right]\right\}
$$

To conclude, GGMs are focused on the assumption that interactions between random variables in a structure may be interpreted as diagrams, with nodes representing variables and edges representing interactions (Cerchiello \& Giudici, 2016). In practice, a stepwise model selection algorithm is used, which begins with a reference model and checks whether an additional edge can be inserted or excluded at each phase using a pairwise statistical testing technique.

In this subsection we examine the network dependence structure between COVID-19, oil price, stock market index, and the economic policy uncertainty. The choice of the different pairs of markets is circumscribed by the data availability. We implement a Gaussian Graphical Model (GGM) analysis to investigate a network structure between variables in order to quantify the strength of the connectedness between them. A GGM contains a couple of 
variables which are shown by circles referring to nodes, and grouping of lines that portrays the connectedness between the variables (Bhushan et al., 2019). The intensity of the connectedness between variables is indicated by the thickness of the lines. However, the thickener the line, the greater the connectedness between variables. The absence of the connectedness between variables is shown by the absence of lines connecting the nodes. For a broader view of the GGM framework please refer to (Friedman et al., 2008), and (Foygel \& Drton, 2010).

A visualization of the network structure for the couples COVID-19-oil, COVID-19-stock, and COVID-19-economic policy uncertainty in the oil-importing and oil-exporting countries is displayed in Figs. 7, 8. Regarding the interconnectedness between COVID-19 and other selected variables interesting findings may be pointed out: (i) COVID-19 has significant

\section{CHINA}

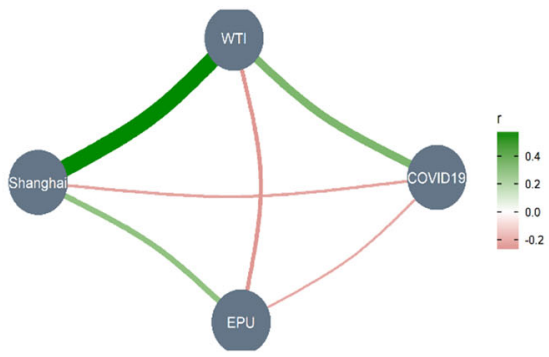

INDIA

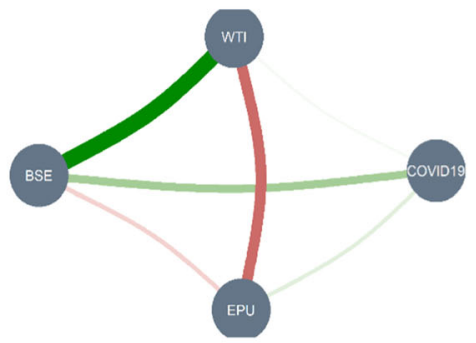

US

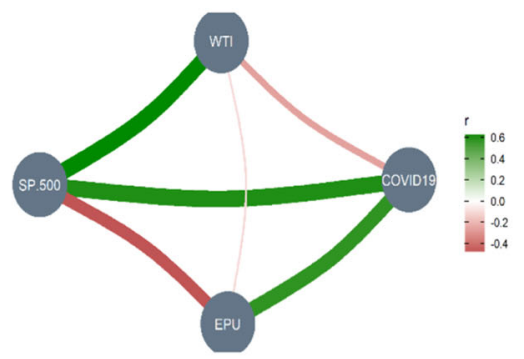

JAPAN

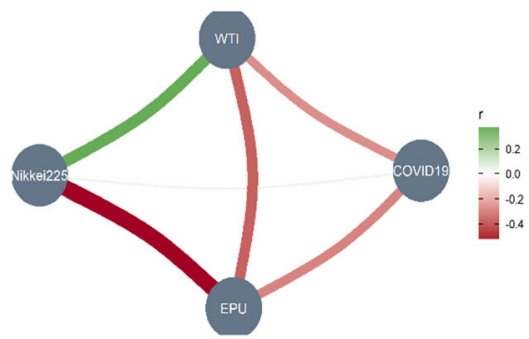

\section{South Korea}

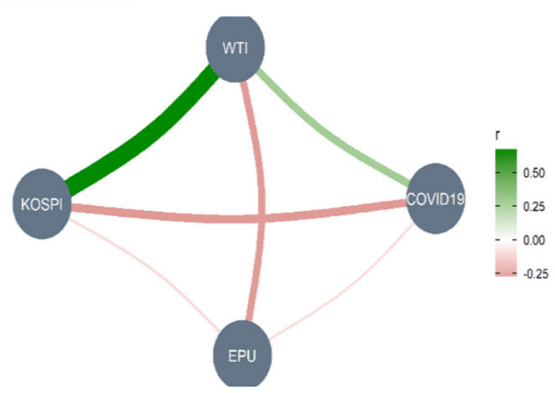

Fig. 7 Network analysis for oil-importing countries. Note: This figure shows the network graph of the causal interplays between variables. The strength of the connectedness between the couples is indicated by the thickness of the lines. The thickener the line, the stronger the connectedness between pairs 

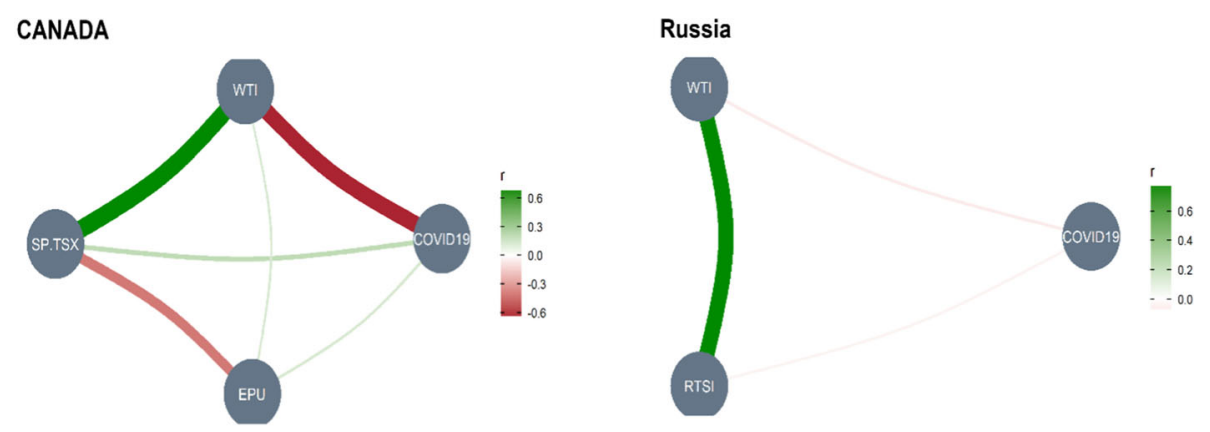

\section{Saudi Arabia}
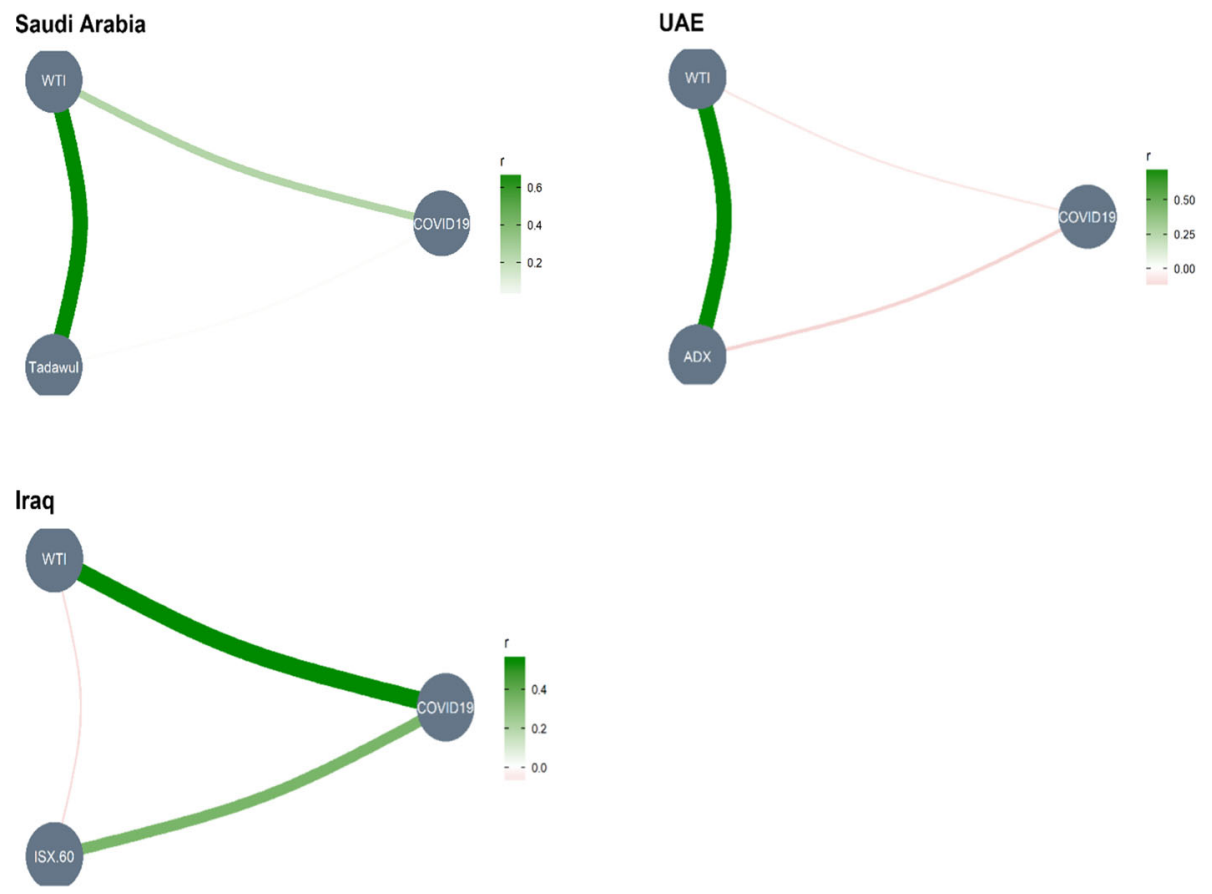

Fig. 8 Network analysis for oil-exporting countries. Note: see note in Fig. 7

strong positive effect on the American stock market (S\&P 500) and economic uncertainty, whereas it negatively causes the Japanese economic uncertainty. (ii) from Fig. 8, for the case of Iraq, as may be expected it is evident to highlight a strong positive causal effect of COVID-19 outbreak in Iraq on the oil price, as shown by very thick line between nodes. (iii) the same pattern as in (ii) was emphasized in the case of Canada, but with a negative sign. (iv) the COVID-19 pandemic has a negative causal effect on the Chinese, Japanese and South Korean economic policy uncertainty, as demonstrated by the red-colored lines between the nodes. (v) overall, the GGM network analysis provides crucial information on the connectedness from COVID-19 to oil price, stock market indices, and economic policy uncertainty, inasmuch as it demonstrates that the new pandemic has a harsh impact on oil, stock markets, and economic uncertainty. 
To deeply analyze the effect of the novel COVID-19 pandemic on the oil price, stock market price indices, and economic policy uncertainty in the oil-importing and oil-exporting countries, we examine the causality interplay and lead-lag nexus between COVID-19 and the other variables through several time scales and frequency bands by using the wavelet tool, which is very helpful in comparison to other classical approaches, inasmuch as it provides various advantages, such as it affords information in the short-, medium-, and long-run investment horizon and produces a comprehensive pattern in the lead-lag connectedness between COVID-19, oil price, stock market indices, and economic policy uncertainty. This would be beneficial in the point of view of policymakers and investors, insofar as it enables to capture how COVID-19, oil, stock markets, and economic uncertainty evolve over different point of times and how they interconnect across several frequency bands.

\section{Discussion for the findings}

\subsection{The connectedness between COVID-19 and oil price}

The findings of the wavelet coherence and phase relation analysis of oil price and COVID-19 pandemic in the oil-importing countries are reported in the form of different maps in Figs. 9, $10,11,12,13$ and that of the oil-COVID-19-19 connectedness in oil-exporting countries are portrayed in Figs. 14, 15, 16, 17, 18. The right panel of each figure refers to the coherence scalogram, whereas the left panel denotes the phase difference maps. The magnitude of the wavelet coherence and phase difference values are shown at the scale of the right of each figure. Higher values of coherence between oil price and COVID-19 pandemic are indicated by red colors. Colder colors refer to low values with deep blue corresponding to the lowest coherence. The regions demarcated by the white lines overlay the $5 \%$ significance level wavelet coherence values. The empirical findings for the Chinese case, the first oil-importing country in the World (22.6\% of overall imported crude oil) are depicted in Fig. 9. As can be seen in Fig. 9, the warmer colors dominate at all wavelet scales and over the entire period of the study, indicating a strong dynamic dependence between oil price and the novel COVID-19 pandemic in China. Additionally, it is noteworthy that the dependence structure between oil
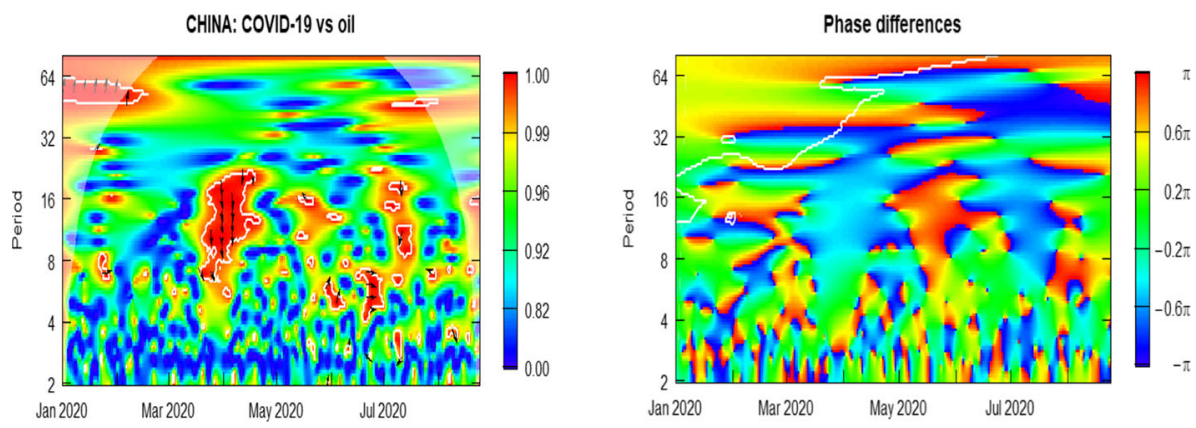

Fig. 9 Wavelet coherence and phase relation between COVID-19 confirmed cases and oil price: The case of China. Note: In the wavelet coherence map the impact of edge effects is indicated by the opaque color region. The bold white lines designate regions of $95 \%$ confidence level statistically significant. The color bar code is a significance of the wavelet strength, with warmer colors referring to high intensity and colder colors denoting low intensity 
US: COVID-19 vs oil

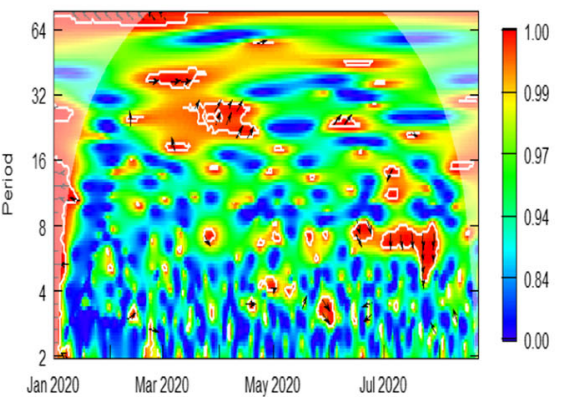

Phase differences

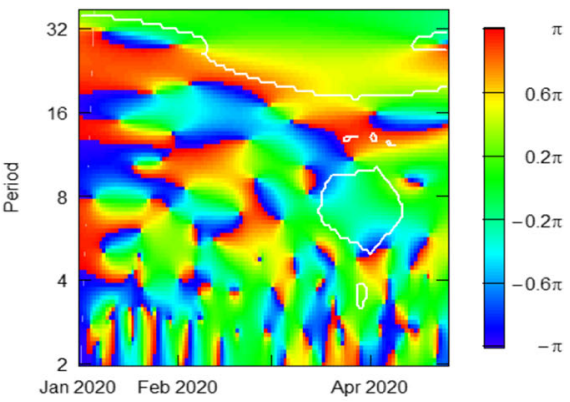

Fig. 10 Wavelet coherence and phase relation between COVID-19 confirmed cases and oil price: The case of US. Note: see notes in Fig. 9
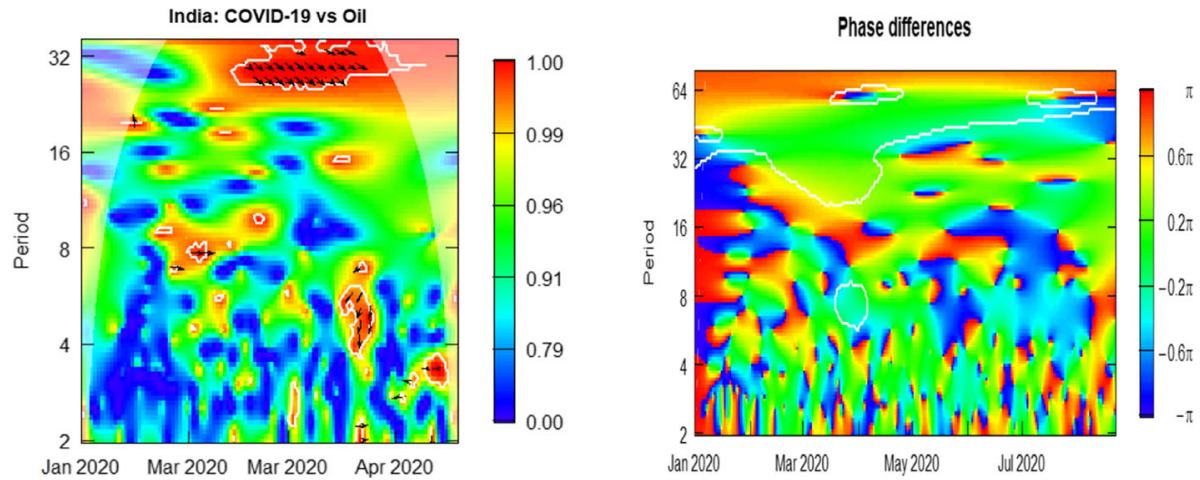

Fig. 11 Wavelet coherence and phase relation between COVID-19 confirmed cases and oil price: The case of India. Note: see notes in Fig. 9
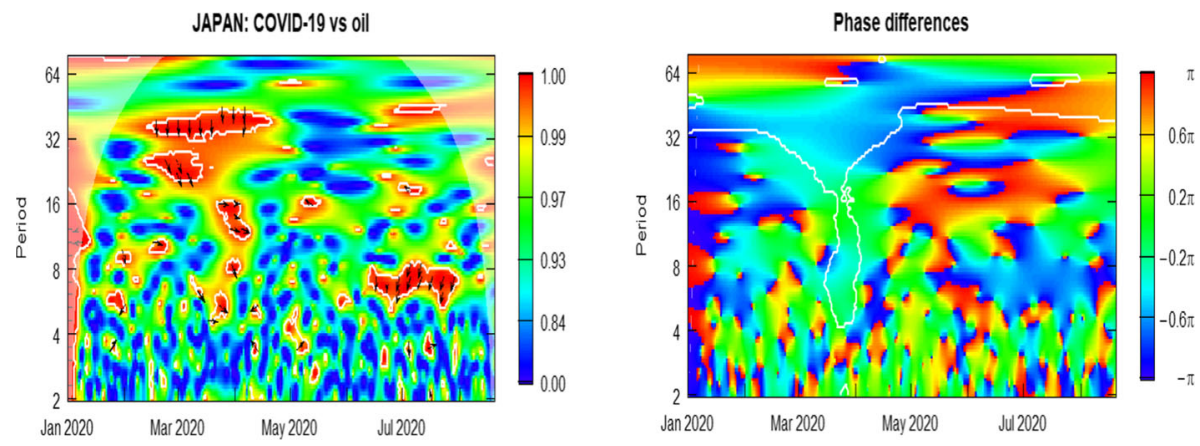

Fig. 12 Wavelet coherence and phase relation between COVID-19 confirmed cases and oil price: The case of Japan. Note: see notes in Fig. 9 

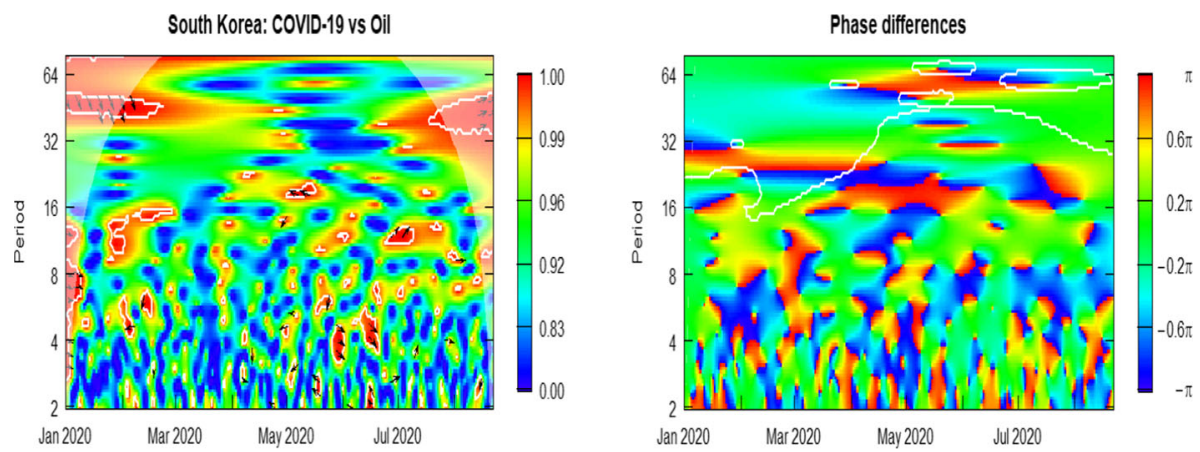

Fig. 13 Wavelet coherence and phase relation between COVID-19 confirmed cases and oil price: The case of South Korea. Note: see notes in Fig. 9

\section{KSA: COVID.19 vs oil}

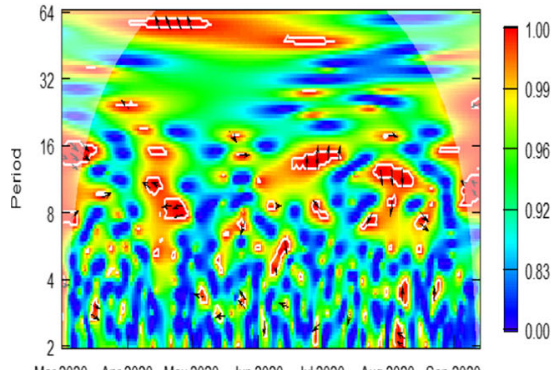

Mar2020 Apr 2020 May 2020 Jun 2020 Jul 2020 Aug 2020 Sep 2020
Phase differences

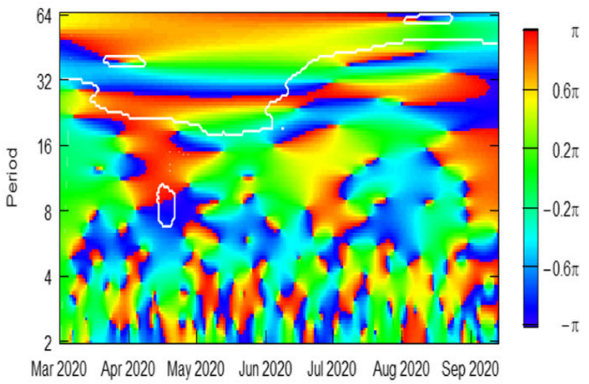

Fig. 14 Wavelet coherence and phase relation between COVID-19 confirmed cases and oil price: The case of Saudi Arabia. Note: see notes in Fig. 9
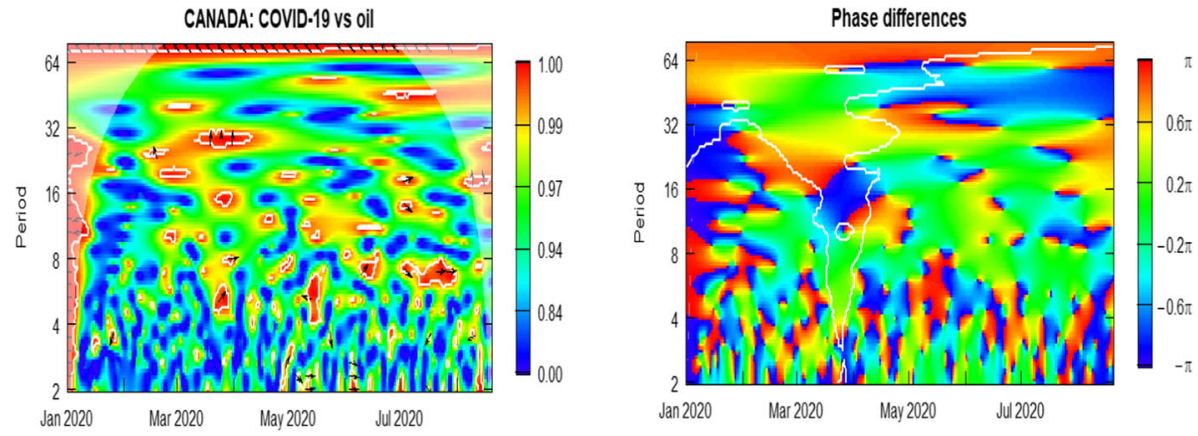

Fig. 15 Wavelet coherence and phase relation between COVID-19 confirmed cases and oil price: The case of Canada. Note: see notes in Fig. 9 

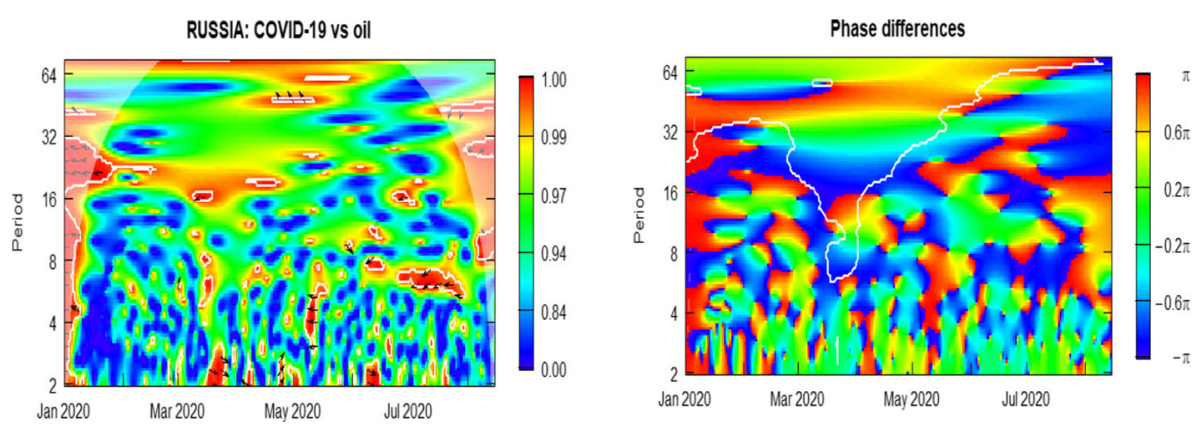

Fig. 16 Wavelet coherence and phase relation between COVID-19 confirmed cases and oil price: The case of Russia. Note: see notes in Fig. 9
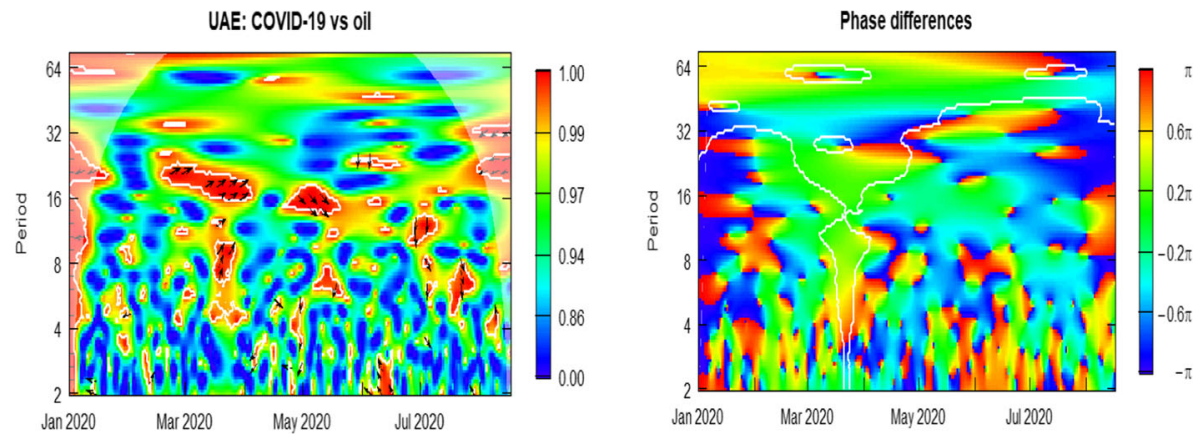

Fig. 17 Wavelet coherence and phase relation between COVID-19 confirmed cases and oil price: The case of UAE. Note: see notes in Fig. 9
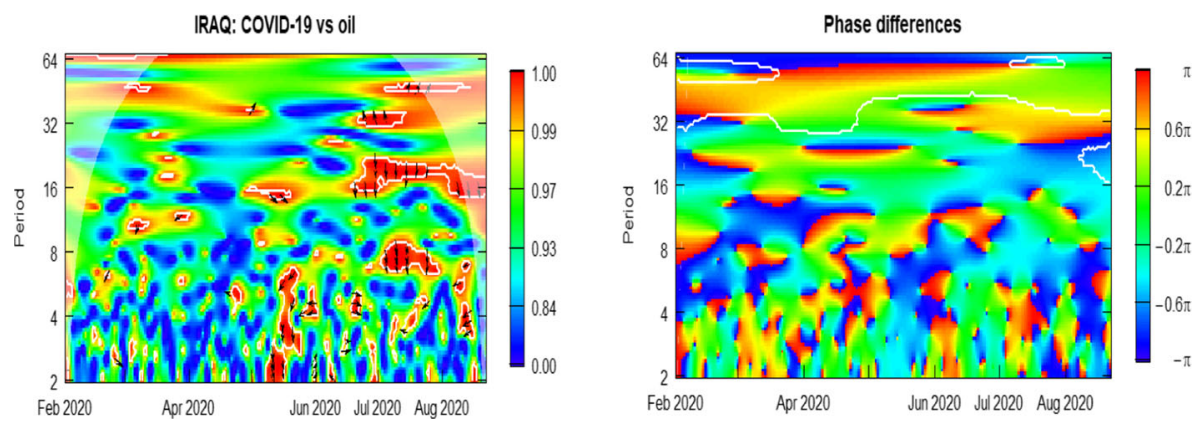

Fig. 18 Wavelet coherence and phase relation between COVID-19 confirmed cases and oil price: The case of Iraq. Note: see notes in Fig. 9

and this pandemic increases throughout wavelet scales. Therefore, one may notice that in the long-term horizon the two variables are more dependent. This may be a plausible explanation of the shock decrease in oil price. A similar pattern is found in Figs. 10, 11, 12, 13 (the cases of US, India, Japan, and South Korea), in which there is the dominance of warmer colors during all periods of times and wavelet scales. Accordingly, it can be highlighted that the 
other oil-importing economies present similar pattern to the Chinese case on the dynamic connectedness between oil price and COVID-19 pandemic, as shown by high coherence levels indicated by the dominance of warmer colors during all periods of times and wavelet scales. Regarding the global phase maps, which indicate the causal direction between oil price and COVID-19 pandemic in the oil-importing countries, the findings emphasize that warmer colors dominate the colder colors, as we observe a plenty of green, yellow and orange islands suggesting that the phase difference values lie between $-0.2 \pi$ and $0.6 \pi$ for the majority of cases. This finding reveals an in-phase relationship during at most all-time periods implying a significant positive dependence between oil price and COVID-19 pandemic.

The findings of the oil-exporting countries are displayed in Figs. 14, 15, 16, 17, 18, respectively for Saudi Arabia, the largest oil-exporting country in the World (13.3\% of exported crude oil), Russia, Iraq, Canada, and UAE. As seen in the scalograms for the wavelet coherence, the novel COVID-19 pandemic in the oil-exporting economies is more coherent with oil price, as revealed by large areas of warmer colors at all wavelet scales and during the entire period of study. However, we may unveil that the rising in the COVID-19 confirmed cases in these countries is highly associated with the decrease in oil prices in the World. The phase relation findings in oil-exporting countries present more complex pattern across time-frequency space. No clear lead-lag connectedness for oil-COVID-19 pairwise is revealed. The in-phase and anti-phase relation patterns are seen for all pairs, with superiority of the antiphase relation scenario. As a matter of fact, more warm-colored islands are mapped with the most phase difference values ranging between $\pi / 2$ and $\pi$, thereby the COVID-19 is leading. This finding may suggest that the causal effects in oil-exporting countries follow those in oil-importing countries and vice versa. Regarding for instance the case of Saudi Arabia, the first largest global oil-producer country, at wavelet scale 8-16 and more, we showed a significant large red-colored area covering at most all-time periods which indicates a leading causal effect from COVID-19 to oil price in the long-term horizon.

In sum, the novel COVID-19 pandemic, both in oil-importing and oil-exporting countries have similar schemes of the connectedness with oil price. It is apparent that the different pairwise present high power of the dependence across wavelet scales and during the period of concern. Our findings are in line with previous recently studies, such as that of Sharif et al. (2020), who's identified high coherence related to COVID-19 bad news in the case of US. Furthermore, the findings have crucial policy implications in the short- and long-term horizons. However, due to COVID-19 crisis investors should be cautious when constructing their international oil portfolios, as well as, policymakers should plan new strategy to struggle against the severe economic consequences of this pandemic.

\subsection{The connectedness between COVID-19 and the stock market indices}

The findings for the wavelet coherent and relation analysis for COVID-19 and the stock market index couples are presented in Figs. 19, 20, 21, 22, 23, 24, 25, 26, 27, 28. As can be seen from the coherence maps, we observe a similar time-scale demeanor for all different COVID-19-stock market pairs. Notably, the warmer color is more significantly pronounced at all frequency bands and from the beginning to the end of the sample for both the oil-importing and oil-exporting countries. Further, regardless of the higher association between COVID19 and the stock market indices at the short-run horizon, the new pandemic is more linked with the stock indices of the oil-importing and oil-exporting countries at mid and long-run horizons. In fact, there are plenty of significant red, orange, yellow, and green small episodes. This finding may indicate that the COVID-19 pandemic immediately and significantly causes 

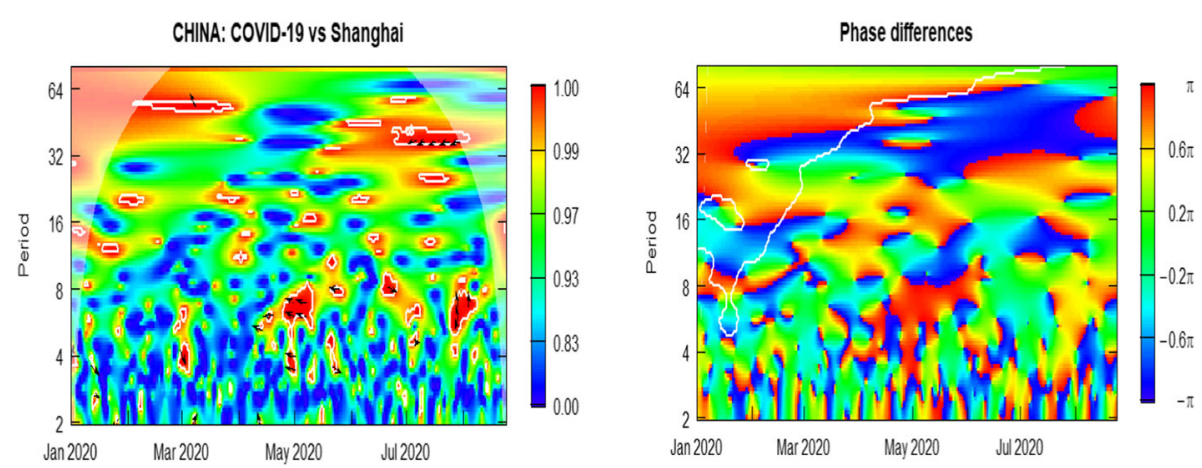

Fig. 19 Wavelet coherence and phase relation between COVID-19 confirmed cases and Shanghai stock index: The case of China. Note: see notes in Fig. 9
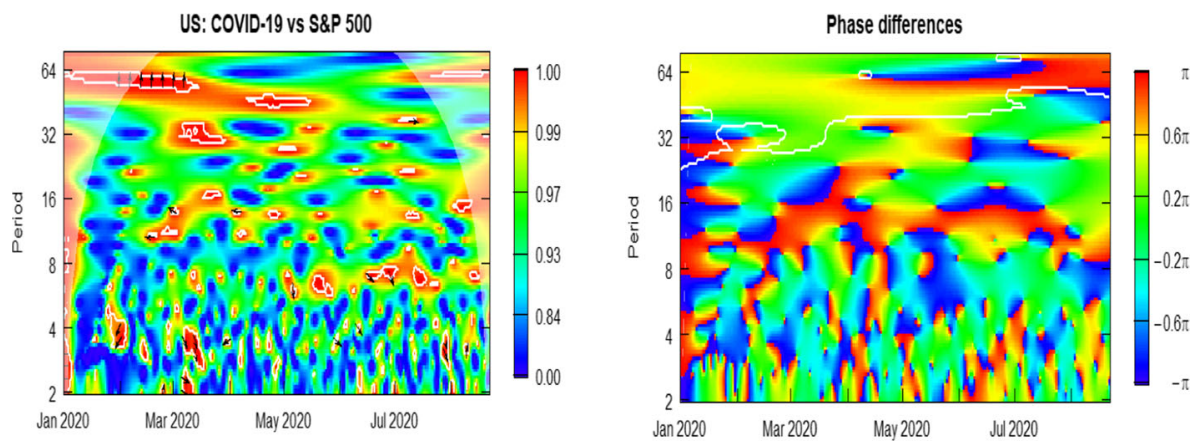

Fig. 20 Wavelet coherence and phase relation between COVID-19 confirmed cases and S\&P 500 stock index: The case of US. Note: see notes in Fig. 9
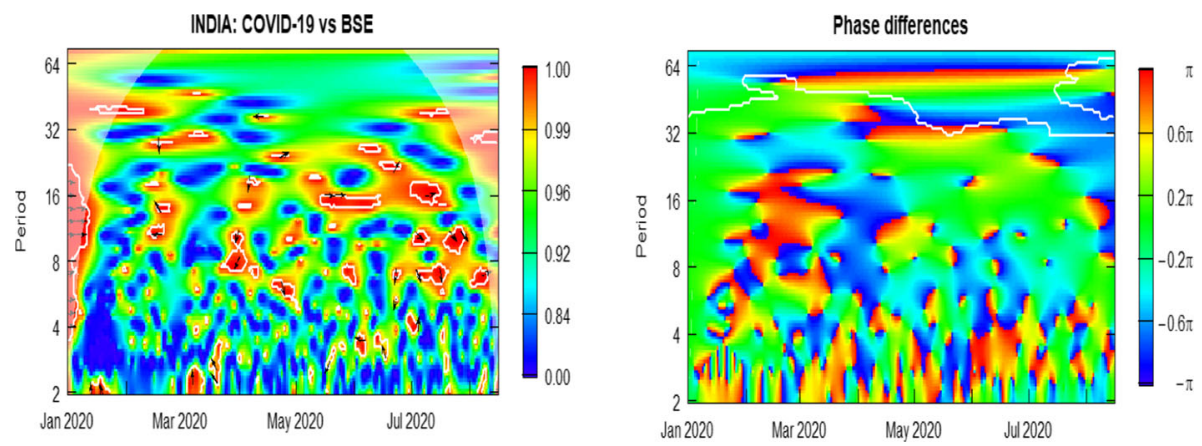

Fig. 21 Wavelet coherence and phase relation between COVID-19 confirmed cases and BSE Sensex stock index: The case of India. Note: see notes in Fig. 9 

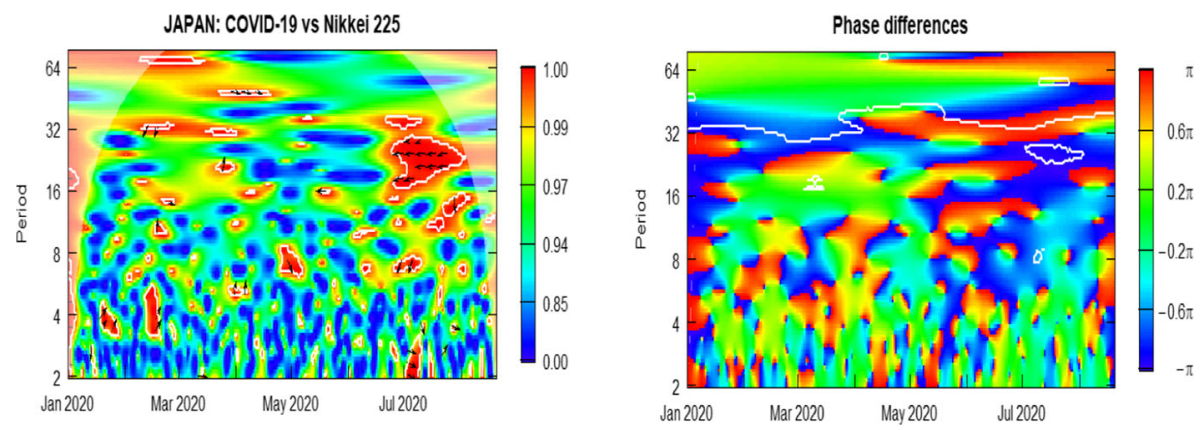

Fig. 22 Wavelet coherence and phase relation between COVID-19 confirmed cases and Nikkei 225 stock index: The case of Japan. Note: see notes in Fig. 9
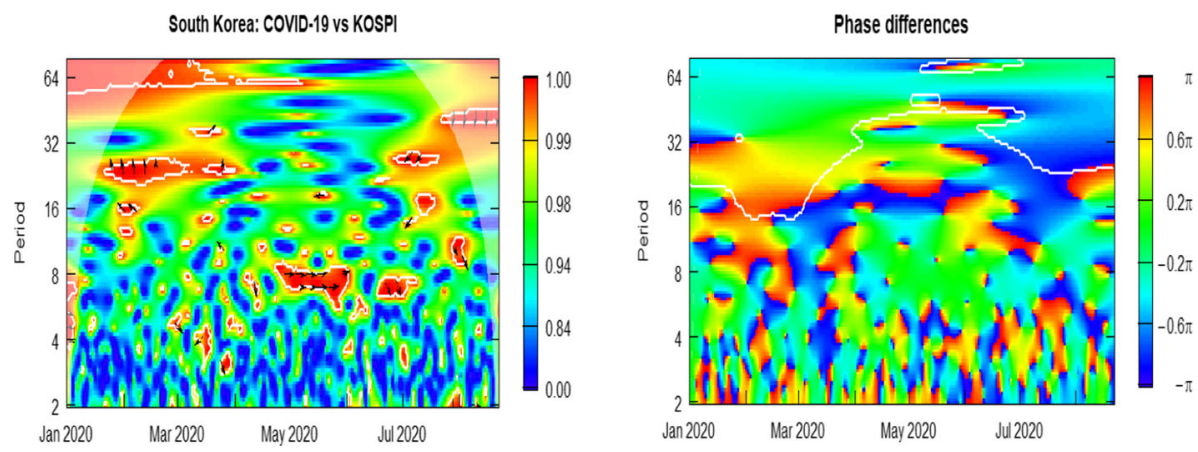

Fig. 23 Wavelet coherence and phase relation between COVID-19 confirmed cases and KOSPI stock index: The case of South Korea. Note: see notes in Fig. 9
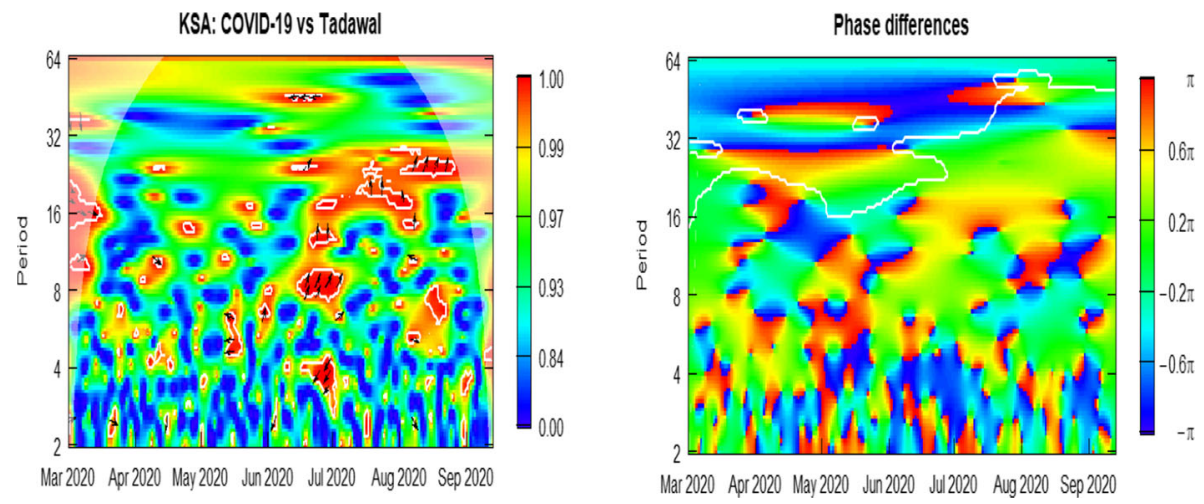

Fig. 24 Wavelet coherence and phase relation between COVID-19 confirmed cases and Tadawul stock index: The case of Saudi Arabia. Note: see notes in Fig. 9 

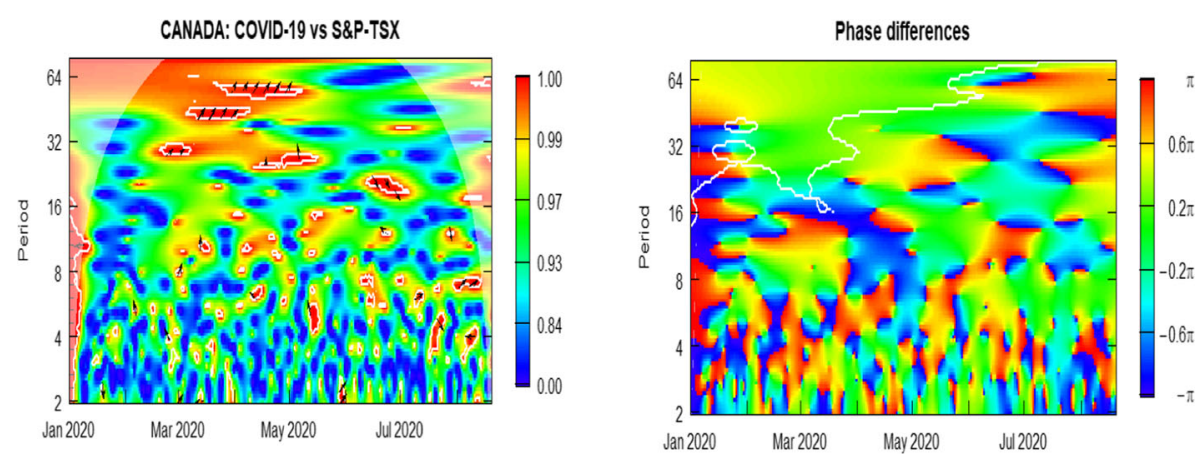

Fig. 25 Wavelet coherence and phase relation between COVID-19 confirmed cases and S\&P-TSX stock index: The case of Canada. Note: see notes in Fig. 9
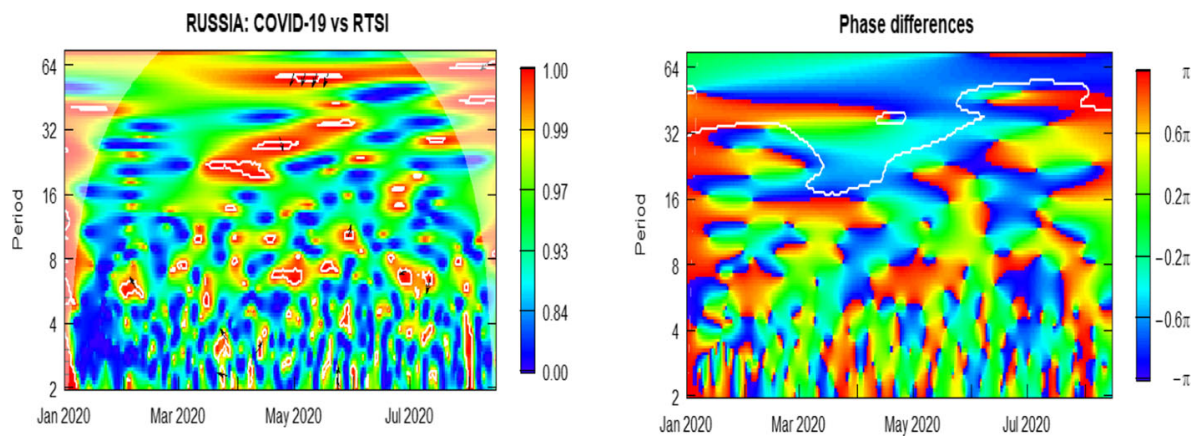

Fig. 26 Wavelet coherence and phase relation between COVID-19 confirmed cases and RTSI stock index: The case of Russia. Note: see notes in Fig. 9
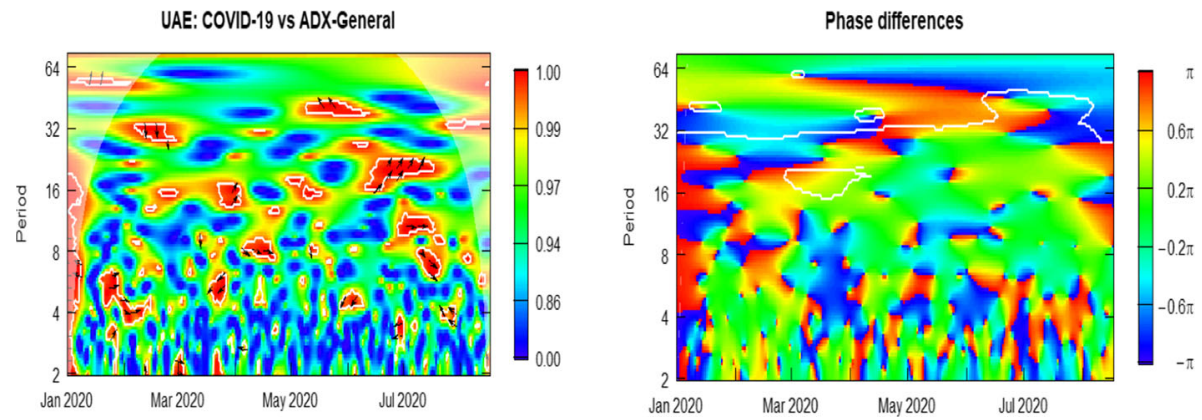

Fig. 27 Wavelet coherence and phase relation between COVID-19 confirmed cases and ADX-General stock index: The case of UAE. Note: see notes in Fig. 9 
IRAQ: COVID.19 vs ISX

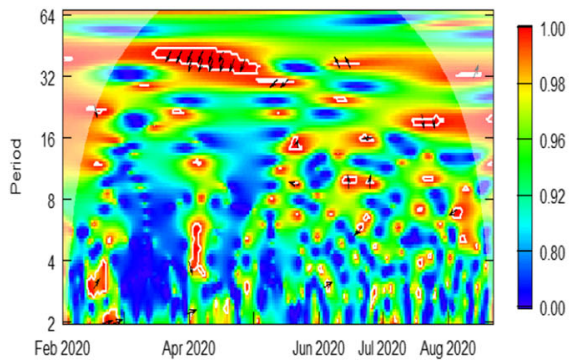

Phase differences

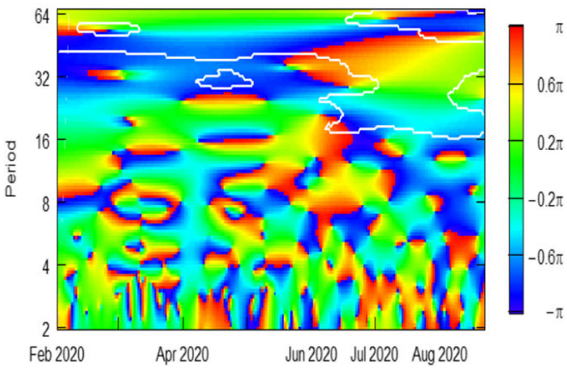

Fig. 28 Wavelet coherence and phase relation between COVID-19 confirmed cases and ISX stock index: The case of Iraq. Note: see notes in Fig. 9

all the top oil-importing and oil-exporting stock market, which exerts severe effects on the real world economy due to the important role of these economies under study to the whole world. Our findings are in line with that of (Sharif et al., 2020) who stated a strong causal effect of the COVID-19 outbreak on the US stock market.

The lead-lag connectedness pattern between the COVID-19 pandemic and the different stock markets is displayed on the right side of each figure (Figs. 19, 20, 21, 22, 23, 24, 25 , $26,27,28)$. It is noticeable that the behavior of the causal effects from the COVID-19 to the oil-importing and oil-exporting stock markets was unstable during the entire sample period. Nevertheless, the global phase relation maps present plenty of significant warm-colored areas with phase difference coefficients ranging between $-\pi / 2$ and $\pi / 2$ indicating an in-phase behavior for the covid-19-stock market dependence structure. Over and above that, at the frequency bands 32-64, in the case of the Chinese, Saudi, Russian, Iraqi, and South Korean stock market, the covid-19 crisis and the different stock market indices move in anti-phase pattern with COVID-19 pandemic lagging. The aforementioned finding may induce that this new pandemic has less pronounced effects on the majority of the oil-importing and oilexporting stock markets in the long-run horizon. However, policymakers and fundamentalists (central banks, big financial institutions, big investors) may manage their portfolios and make beneficial hedging strategies in the long-run.

Summing up the findings for the COVID-19-stock market connectedness in the oilimporting and oil-exporting countries, it is important to notice that the new pandemic significantly and strongly affecting all the stock markets under concern at all frequency bands and from the beginning to the end of the sample period. Accordingly, our findings are worthwhile for the authorities of the oil-importing and oil-exporting countries on how understanding the direction of the transmission mechanism between the novel pandemic and the different stock markets, and therefore making good strategy decisions for striving towards covid-19 crisis.

\subsection{The connectedness between COVID-19 and the economic policy uncertainty}

The time-varying connectedness between COVID-19 pandemic and the economic policy uncertainty in the oil-importing and oil-exporting countries is discussed in this subsection. We examined the wavelet coherence and phase relation for the following countries based on the availability of the economic policy uncertainty data: China, US, India, Japan, South Korea, and Canada. The corresponding graphs are presented in Figs. 29, 30, 31, 32, 33, 34. As shown 

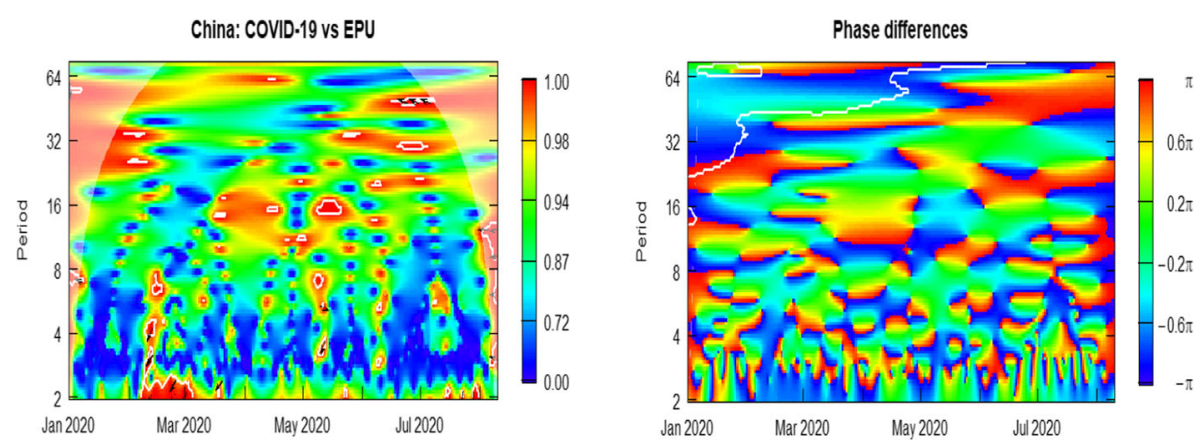

Fig. 29 Wavelet coherence and phase relation between COVID-19 confirmed cases and the Economic Policy Uncertainty: The case of China. Note: see notes in Fig. 9

US: COVID-19 vs EPU

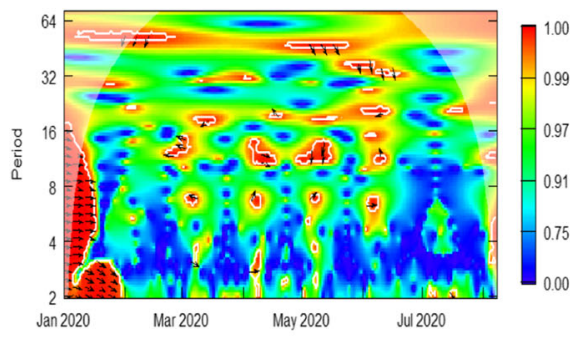

Phase differences

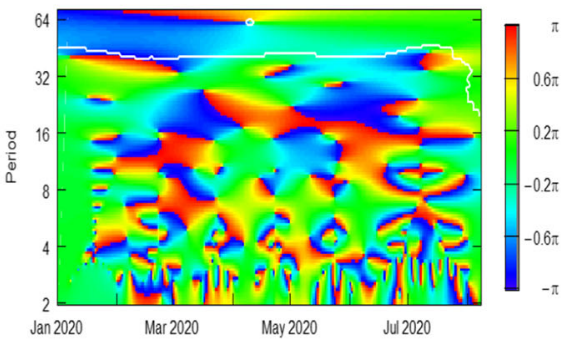

Fig. 30 Wavelet coherence and phase relation between COVID-19 confirmed cases and the Economic Policy Uncertainty: The case of US. Note: see notes in Fig. 9
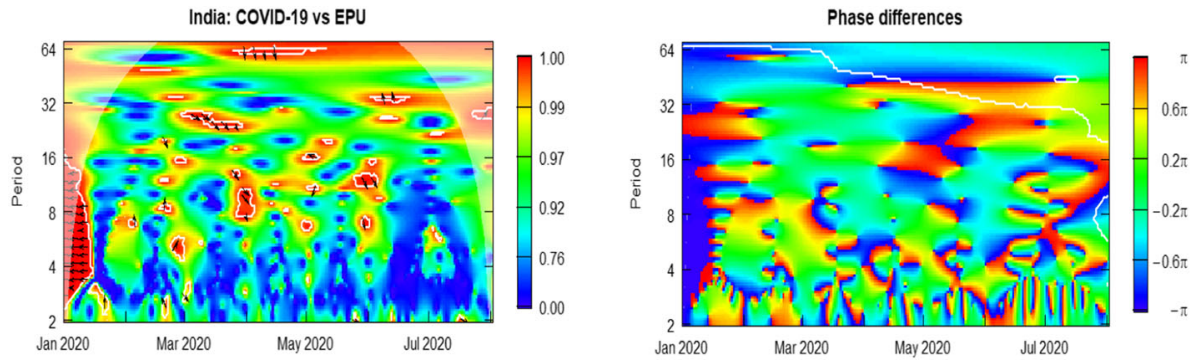

Fig. 31 Wavelet coherence and phase relation between COVID-19 confirmed cases and the Economic Policy Uncertainty: The case of India. Note: see notes in Fig. 9

from the coherence graphs various prominent findings revealed. Firstly, at the beginning of the time period we observe a large significant red island for the frequency bands 2-4, 4-8, and 8-16 for US, India, Japan, South Korea, and Canada. Accordingly, this finding point for great coherence between covid-19 outbreak and the economic policy uncertainty at both short and medium run investment horizon, which may support the fact that COVID-19 pandemic has an immediate effect on the economic policy uncertainty of the oil-importing and oil-exporting countries. Secondly, in all country cases the hot colors are more pronounced in the mid- and 

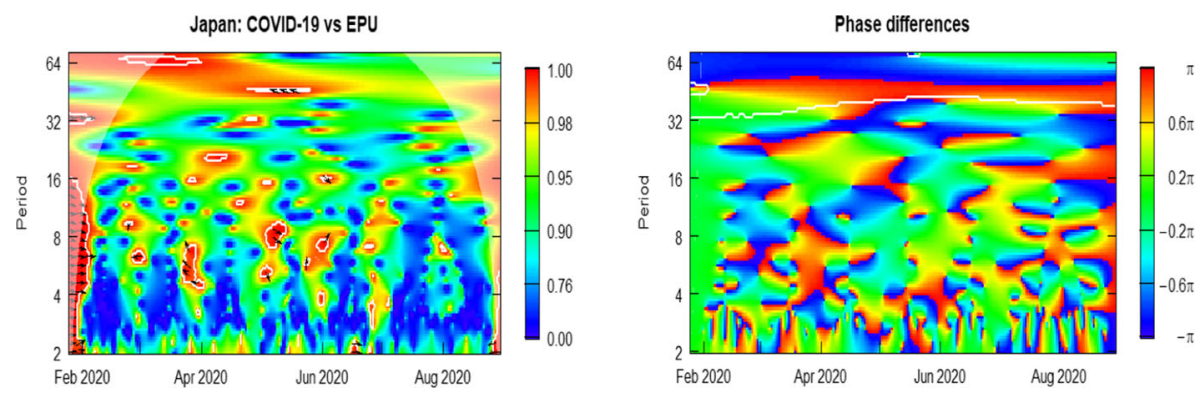

Fig. 32 Wavelet coherence and phase relation between COVID-19 confirmed cases and the Economic Policy Uncertainty: The case of Japan. Note: see notes in Fig. 9
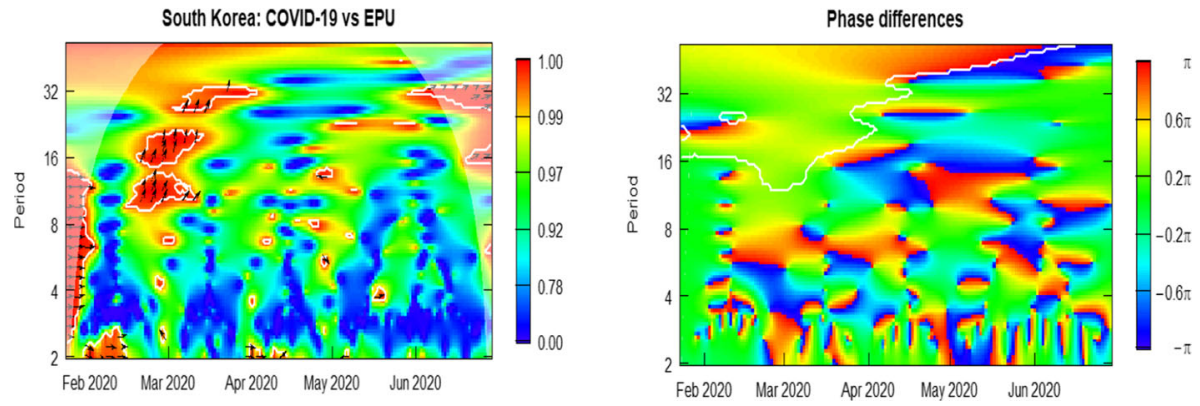

Fig. 33 Wavelet coherence and phase relation between COVID-19 confirmed cases and the Economic Policy Uncertainty: The case of South Korea. Note: see notes in Fig. 9
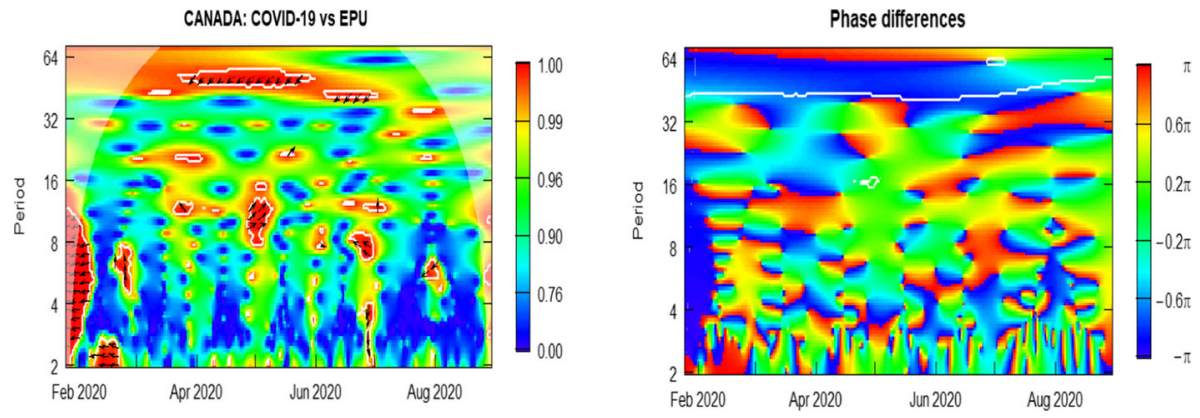

Fig. 34 Wavelet coherence and phase relation between COVID-19 confirmed cases and the Economic Policy Uncertainty: The case of Canada. Note: see notes in Fig. 9

long-run horizon for the entire sample period indicating that the effect of COVID-19 crisis on the economic policy uncertainty persists for longer time scales. Thirdly, at the frequency band 2-4 days the coherence maps reveal huge blue-colored zones spanning from mid-April to the end of the sample period which implies short-run weak causal effect for the COVID-19 on the economic policy uncertainty. Finally, regarding the coherence structure for COVID-19 pandemic and the economic policy uncertainty our findings support the findings of Sharif 
et al. (2020), who stated greater effect of covid-19 outbreak on the US economic uncertainty over several time points and time scales.

Looking at the global phase relation behavior for COVID-19 outbreak and the economic polity uncertainty, it is noteworthy that there is no clear lead-lag connectedness between the variables. One may provide evidence that the in-phase behavior is dominant during the entire sample period, thereby uncovering an accurate procyclical pattern. Furthermore, from the phase relation maps it is apparent that the green- and yellow-colored zones dominate, we highlight a huge green and yellow islands indicating a phase difference values ranging between 0 and $\pi / 2$. This is an indication of leading behavior of COVID-19 pandemic. As far as one may evidence that the Chinese, US, Indian, Japanese, South Korean, and Canadian economic uncertainties precede the time-varying dynamics of COVID-19 crisis.

\subsection{The continuous wavelet-based Value-at-Risk analysis}

In this section, we illustrate the dynamics of the dependence between COVID-19 risks towards both oil and stock market risk measures in oil-importing and oil-exporting countries. To do so, we have combined the continuous wavelet transform (CWT) and Value-at-risk (VaR) analyses. In modern financial risk management, $\mathrm{VaR}$ is one of the most commonly used tools for measuring risks in finance, banking, and insurance. This measure is essentially applied in finance system to hedge major losses alternatives. Obviously, VaR is defined as the measure that quantifies the worst expected losses at a given confidence level $\alpha \in(0,1)$ and is expressed as follows:

$$
\operatorname{VaR}_{t}(\alpha)=\mu_{t}+\hat{\sigma}_{t \mid t-1} \times t^{-1}(\alpha)
$$

where $\mu_{t}$ is the mean, and $\hat{\sigma}_{t \mid t-1}$ refers to the conditional standard deviation extracted from $\operatorname{GARCH}(1,1)$ estimation given the information at $t-1 . t^{-1}(\alpha)$ captures the $\alpha-$ quantile of the data for student distribution.

For the computations, we obtained the return series of oil and stock market index prices as $r_{t}=\log \left(p_{t} / p_{t-1}\right)$. Where $p_{t}$ and $p_{t-1}$ represent the prices of day $t$ and $t-1$, respectively. Among the oil-exporting countries we studied were Canada, Saudi Arabia, Russia, and United Arab Emirates. Meanwhile, the oil-importing countries considered were the United States, Japan, South Korea, and China. Due to the voluminous findings of this study, the results related to the cases of Iraq (oil-exporting country) and India (oil-importing country) are available upon request.

In order to obtain stationary time series, we defined a proxy for the COVID-19 pandemic at each country $i$ and day $t$. The number of confirmed COVID-19 cases divided by the population size is called the infection rate (INFR):

$$
I N F R_{t}^{i}=\frac{\text { Number of COVID }-19 \text { cases }}{\text { Population size }}
$$

At first, we fit a univariate $\operatorname{GARCH}(1,1)$ model for each time series defined above. Thereafter, we used the obtained time-varying estimated standard deviations to compute the time-varying VaR coefficients. The values of VaR measures are extracted from Eq. 14. Lastly, we extracted the wavelet coherence and phase-difference coefficients of the VaR series from Eqs. 9, 10. The results are displayed in the heatmaps of Figs. 37, 38, 39, 40 in "Appendix B".

From the heatmaps given in Fig. 37, we observed strong co-movements between COVID$19 \mathrm{VaR}$ risk and WTI oil VaR risk over time and frequencies. Interestingly, the causal relation 
between COVID-19 and WTI VaR risks is more pronounced at the beginning and end of the sample period, indicating the persistence of risk spillover transmission between the COVID19 pandemic and oil price returns. Further, it is worth noting that the lead/lag relationship between the different VaR pairs is heterogenous throughout time and frequencies with the dominance of leading effect from VaR-COVID-19 to VaR-WTI. This suggests that a high COVID-19 pandemic VaR risk leads to a high oil price VaR risk.

A look at Fig. 38, which corresponds to the case of oil-importing countries, shows high degree of coherence between the different VaR pairs at high and medium frequencies and during the first month of the study. This does not include China which has a strong comovement between risks persisting during the whole period at the shortest scale. This is an indication that China is more affected by the novel pandemic than other countries like US, Japan, South Korea, and India in the period under concern. Furthermore, we may uncover that COVID-19 risk immediately translates to oil price risk in China. Another important finding drawn from the oil-importing case is that the in-phase behavior between VaR pairs is dominant, with VaR-COVID-19 leading as shown by the arrows pointing towards right and down.

Overall, the coherence between VaRs of the COVID-19 pandemic and that of the WTI oil price returns in oil-exporting and oil-importing countries is significant and highly suggestive of strong co-movements from the risk associated with the pandemic to the risk linked with oil price returns. Accordingly, investors, decision makers, market participants, and portfolio managers should pay further attention to the risk management associated with the COVID-19 pandemic and oil prices.

The Fig. 39 portraying the coherence between VaR-COVID-19 and VaR-stock index returns in oil-exporting countries yields interesting results. The heatmaps show pockets of significant coherence between $\mathrm{VaR}$ variables. This may point out high co-movement between VaR-COVID-19 and VaR-stock index returns in oil-exporting countries. For instance, a significant high causal relation between COVID-19 risk and Canadian stock market risk is observed during the first two weeks of April 2020 at 1-2 day time scales. For the 32-48 frequency bands and during the period covering January 26, 2020 to May 25, 2020, the upward right-positioned phase angles show that COVID-19 risks lead to Canadian stock market VaR risks.

The coherence between VaR pairs in oil-importing countries is depicted in Fig. 40. The results reveal several significant red islands, suggesting strong co-movements between COVID-19 VaRs and the oil-importing stock market VaRs at different frequency bands and time periods. As for the phase relation, the results also exhibit an unclear pattern for the lead/lag relationship between VaRs. In general, the proposed wavelet-based VaR analysis allows us to examine the degree and the direction of the co-movement between COVID-19 risks and both oil and stock market index risks in oil-exporting and oil-importing countries. This examination is helpful for investors, portfolio managers, and decision makers.

\section{Conclusion and policy implications}

This empirical research sheds novel light on the dynamic dependence structure between three pairs COVID-19-oil price, COVID-19-stock market index, COVID-19-economic policy uncertainty in the most important oil-producers and oil-consumers countries in the World. We employed the wavelet coherence and phase relation frameworks as it explores the strength, the causality directions, and the lead-lag relationships from COVID-19 to oil price, stock market 
price, and to the economic policy uncertainty. It is found that the intensity of coherence is strong across time-scales domain, and it increases from the short- to long-term horizon. The short-term effect of COVID-19 in oil-importing and oil-exporting countries on oil price is weaker than the long-term effect, which may suggest that making good long-term strategy interventions of the governments under study enables the oil market to recover slowly in the long-term horizon.

According to the perspective of risk management, our findings evidence that COVID19 pandemic has a strong medium and long-run causal effect on the oil price, stock market indices, and the economic uncertainty for both the oil-importing and oil-exporting economies. However, the persistence of the causal effects of the new pandemic may lead these countries to intervene and help investors, policymakers, and financial managers to handle several market risks caused by the COVID-19 outbreak. Albeit the COVID-19 is yet ongoing, the authorities for the top oil-consumers' and oil-producers' countries may schedule good adapting strategies.

Our empirical findings provide interesting policy implications for policy makers regarding the prevention of risk transmission emerging from the COVID-19 pandemic. Further, our study may give advice to different kinds of investors (short-, medium-, and long-run investors) about hedging strategies against high levels of economic policy uncertainty. For policy makers, owing to the high levels of time-varying causal effects of the COVID-19 crisis on oil and stock market prices in both oil-importing and oil-exporting countries, the governments of these countries should be aware of the risk contagion effect that occurred in the various pairs: COVID-19-oil and COVID-19-stock market pairs, especially in the longrun horizon (large wavelet scale). Therefore, the oil-importing and oil-exporting authorities should undertake strong and efficacious interventions to minimize the risk generated by the COVID-19 pandemic. Furthermore, the other countries of the world, in particular those with oil-exporter or oil-importer economies, should learn lessons from the cases used in our study. Finally, for the authorities in general, our findings are convenient because they will assist with acquiring a better comprehension of the dynamic causal effects of COVID-19 on oil prices, stock market prices, and economic policy uncertainty.

In contrast, from the investor's point of view, the current study is not encouraging, especially for long-run investors trying to realize diversification benefits over the oil-importing and oil-exporting countries' stock markets due to a highly dynamic dependence of the COVID-19 pandemic, on one side, and oil and stock market prices, on the other side, which is expected owing to the extreme circumstances of the COVID-19 pandemic and its evolution to the numerous novel variants.

The present study revisits the time-varying dependence structure and causal interplays between COVID-19, oil prices, stock market prices, and economic policy uncertainty and focuses on only a limited number of oil-importing and oil-exporting countries. Thus, because the COVID-19 pandemic is worldwide, future research can be extended to a large number of countries, such as the G20 countries, the eurozone, and so on. Further, the empirical findings of the current study are crucial, and it is noted that issues related to the COVID-19 pandemic still deserve more attention and different directions in future studies. Thus, it is important to increase the data regarding new strains of COVID-19.

In addition, future empirical studies can also be conducted on this subject by examining an analysis based on the effects of the COVID-19 pandemic in several sectors, for instance, health care, tourism, airlines, and so on. These studies may uncover more detail about the dynamics of the causal effect of the COVID-19 pandemic in the different sectors, which is important for investors and policy makers. The major limitation of the wavelet approach employed in our study is that it is restricted to a univariate or bivariate analysis (two time 
series). A multiple wavelet cross-correlation analysis would perhaps be important to address in future research.

Acknowledgements We are grateful to the Guest Editor and the anonymous referees for their constructive and helpful comments that allowed us to improve the paper. we remain solely responsible for errors, if any.

\section{Appendix A}

See Figs. 35, 36. 

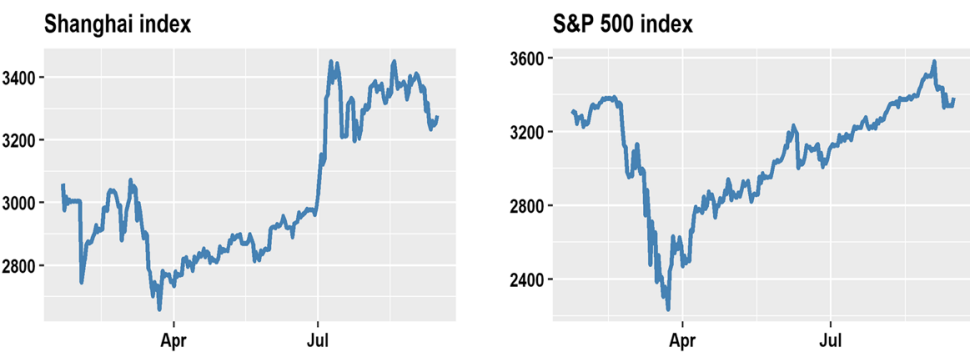

BSE Sensex index

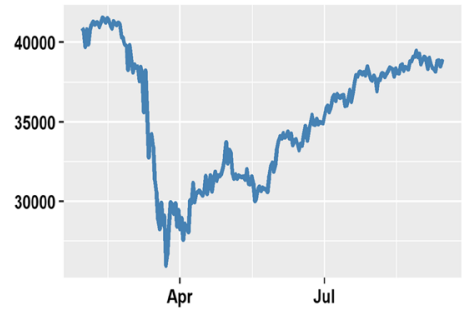

NIKKEl 225 index

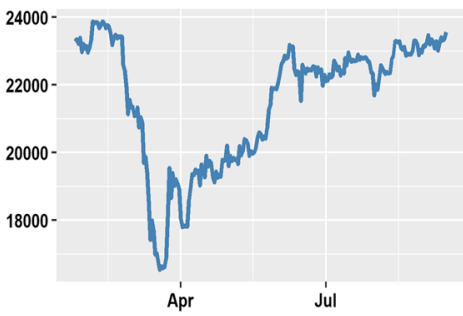

Tadawul index
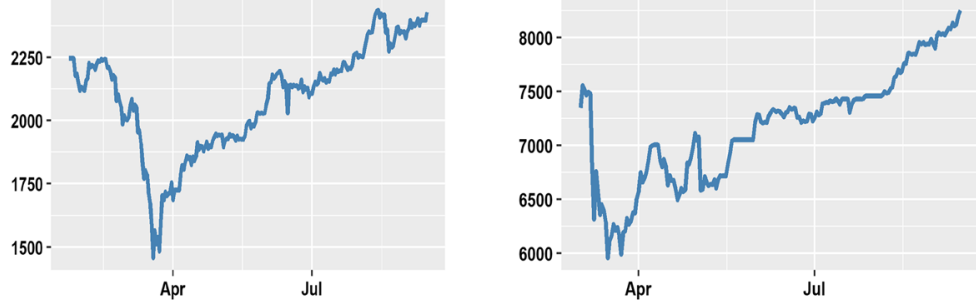

S\&P-TSX index
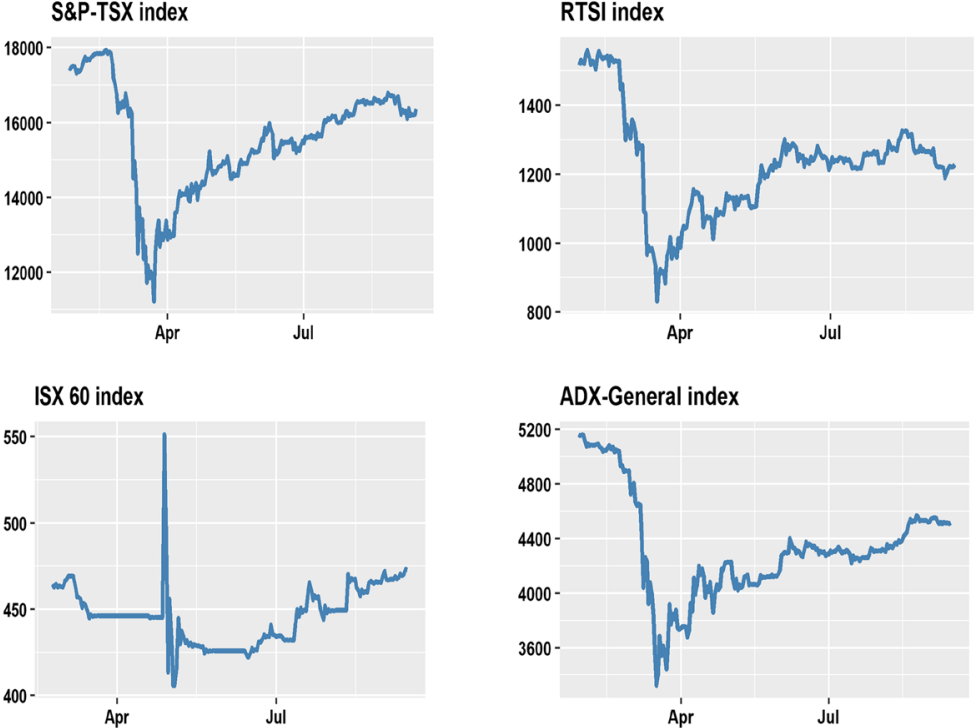

Fig. 35 Stock market index changes during the covid-19 pandemic 


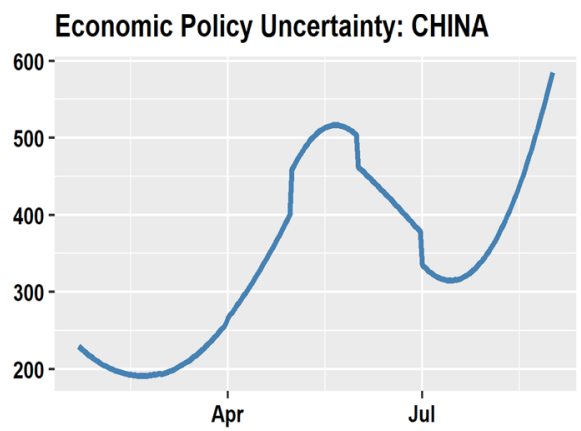

Economic Policy Uncertainty: INDIA

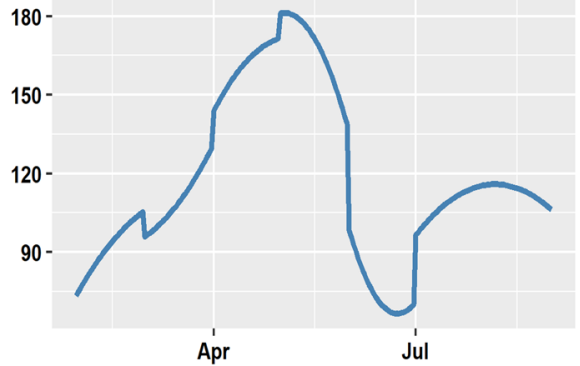

Economic Policy Uncertainty: S.KOREA

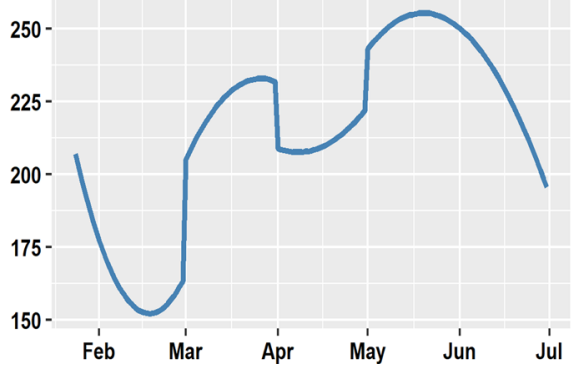

\section{Economic Policy Uncertainty: US}

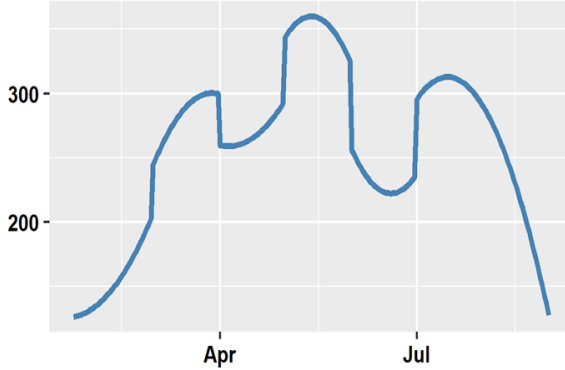

Economic Policy Uncertainty: JAPAN

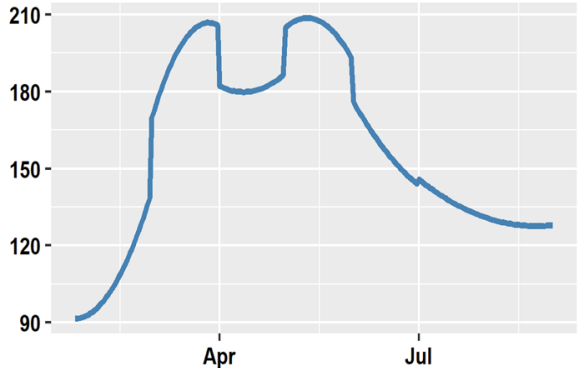

\section{Economic Policy Uncertainty: CANADA}

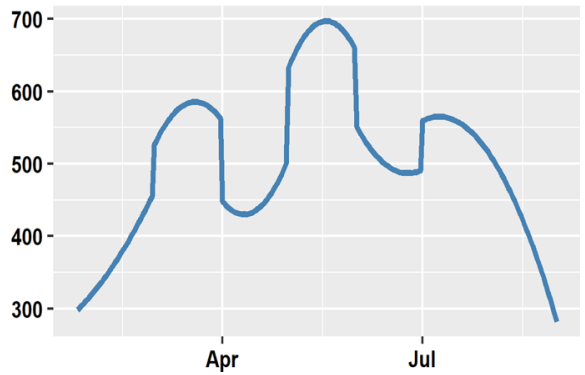

Fig. 36 The evolution of the economic policy uncertainty during the covid-19 pandemic

\section{Appendix B}

See Figs. 37, 38, 39, 40. 

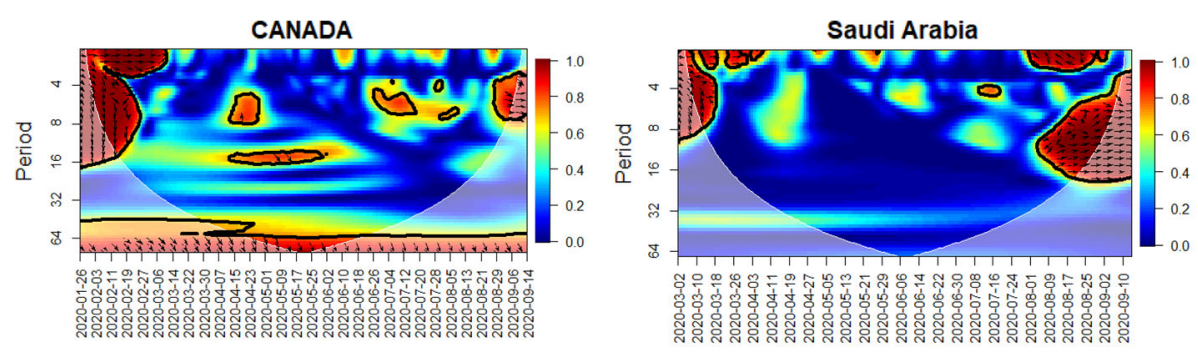

RUSSIA
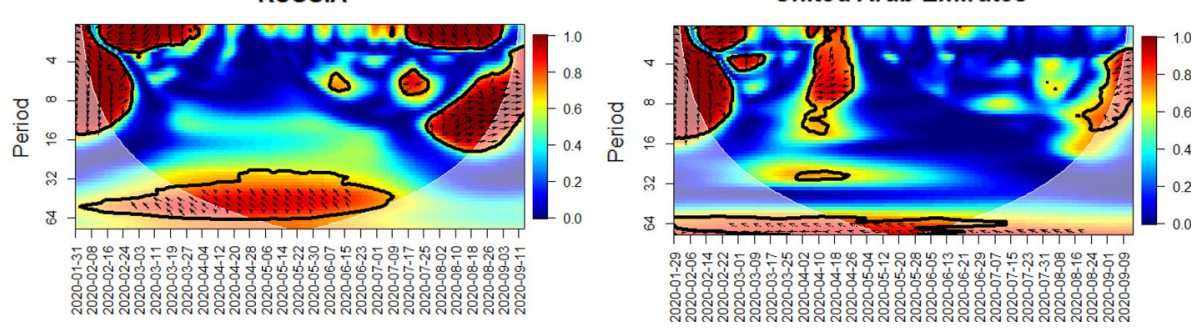

Fig. 37 The wavelet coherence of VaR-COVID-19 vs VaR-WTI in the case of oil-exporting countries. This figure plots the wavelet coherence and phase relation of pairs consisting of VaR of COVID-19 and VaR of WTI oil price returns in oil-exporting countries. The horizontal axis represents time, whereas the vertical axis represents frequency (the lower the frequency, the greater the scale). The color bar on the right side of each map shows the degree of dependence between VaRs. Deep red is the warmest color, while deep blue is the coolest color. The warmer the color, the higher the coherence between variables. The lead/lag phase relationship between the two VaRs is indicated by arrows. Arrows pointing to the right indicate that the VaR series are in-phase. Arrows pointing to the left indicate that the VaR series are anti-phase. Arrows pointing down and to the right, or up and to the left demonstrate a leading behavior of the first variable. Arrows pointing to the right-up or left-down indicate that the second variable is leading

CHINA

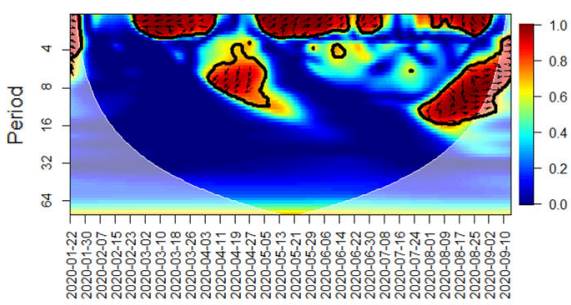

SOUTH KOREA

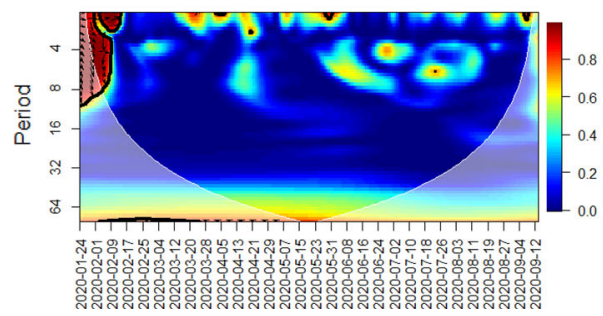

JAPAN

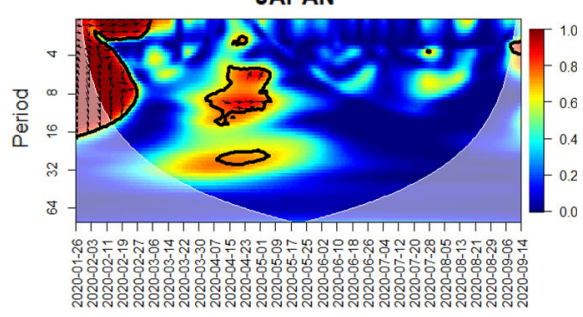

United States

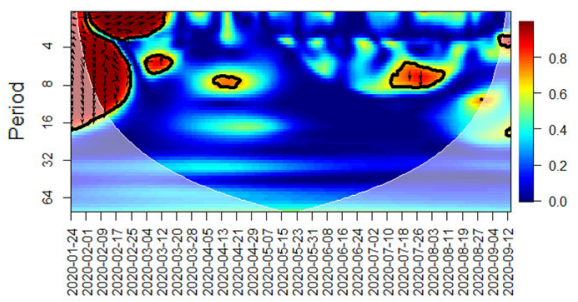

Fig. 38 The wavelet coherence of VaR-COVID-19 vs VaR-WTI in the case of oil-importing countries. This figure plots the wavelet coherence and phase relation of pairs consisting of VaR of COVID-19 and VaR of WTI oil price returns in oil-importing countries. See notes in Fig. 37 

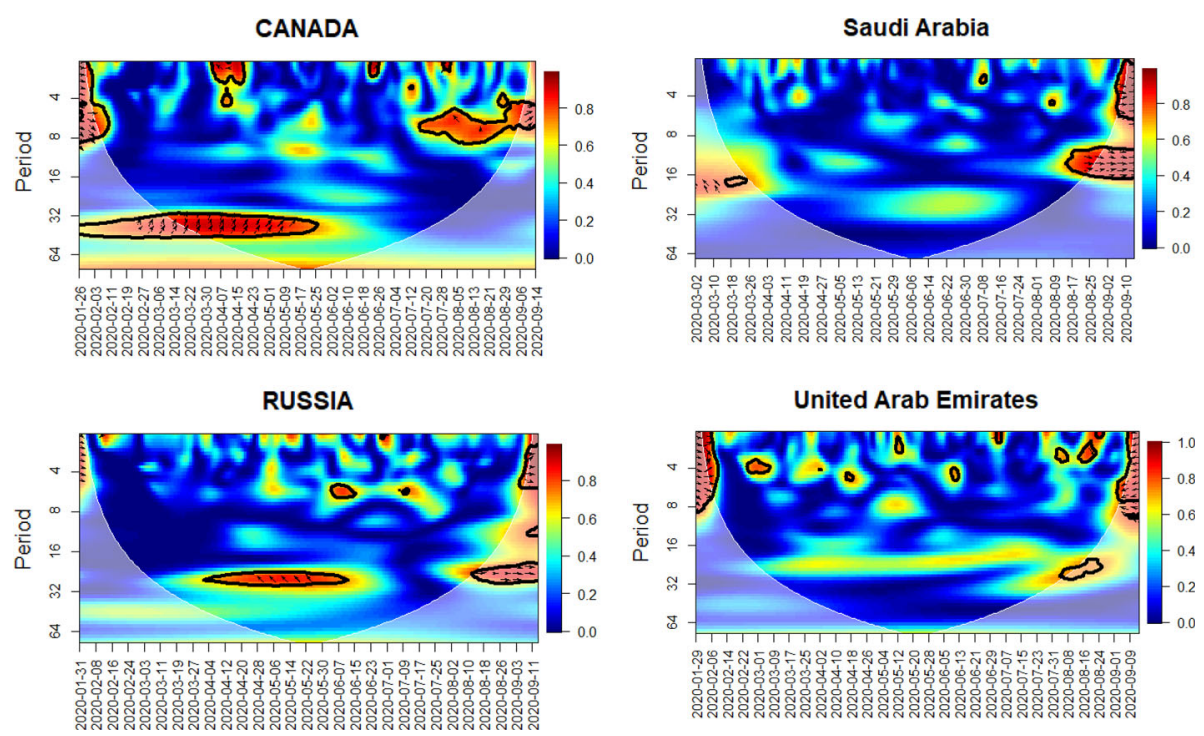

Fig. 39 The wavelet coherence of VaR-COVID-19 vs VaR-stock index in the case of oil-exporting countries. This figure plots the wavelet coherence and phase relation of pairs consisting of VaR of COVID-19 and VaR of stock index price returns in oil-exporting countries. See notes in Fig. 37
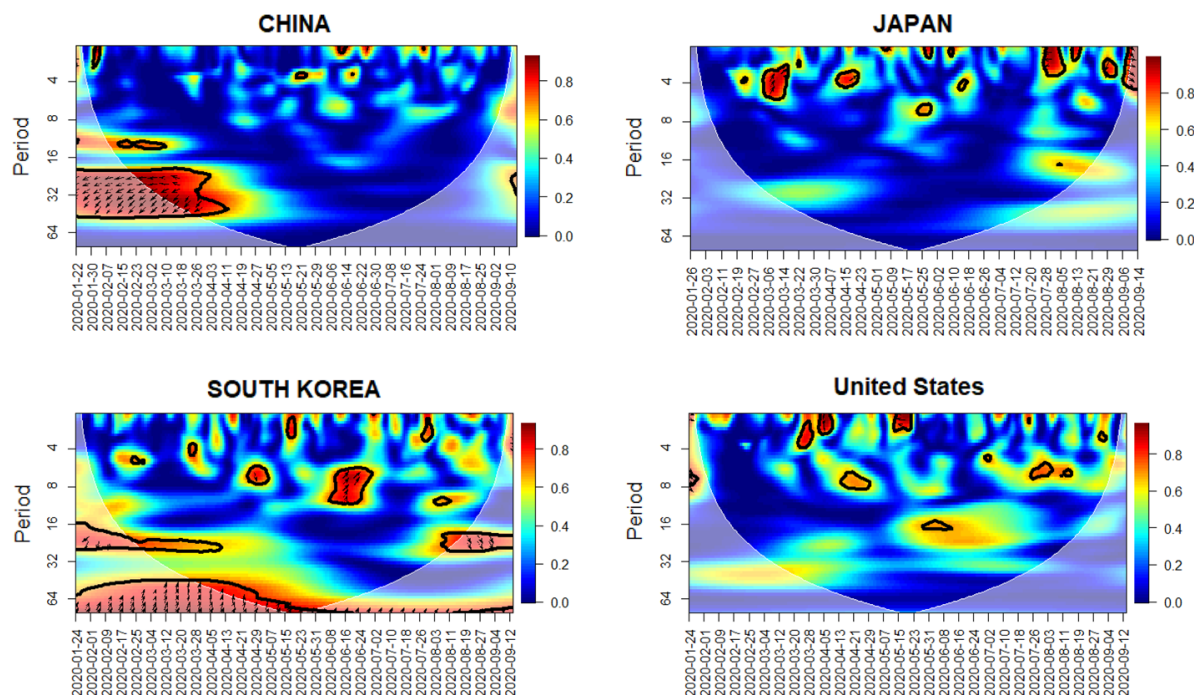

Fig. 40 The wavelet coherence of VaR-COVID-19 vs VaR-stock index in the case of oil-importing countries. This figure plots the wavelet coherence and phase relation of pairs consisting of VaR of COVID-19 and VaR of stock index price returns in oil-importing countries. See notes in Fig. 37 


\section{References}

Aguiar-Conraria, L., Azevedo, N., \& Soares, M. J. (2008). Using wavelets to decompose the time-frequency effects of monetary policy. Physica A: Statistical Mechanics and its Applications, 387(12), 2863-2878. https://doi.org/10.1016/j.physa.2008.01.063

Aguiar-Conraria, L., Martins, M. M. F., \& Soares, M. J. (2012). The yield curve and the macro-economy across time and frequencies. Journal of Economic Dynamics and Control, 36(12), 1950-1970.

Aguiar-Conraria, L., \& Soares, M. J. (2014). The continuous wavelet transform: Moving beyond uni- and bivariate analysis. Journal of Economic Surveys, 28(2), 344-375. https://doi.org/10.1111/joes.12012

Alamgir, F., \& Amin, S. Bin. (2021). The nexus between oil price and stock market: Evidence from South Asia. Energy Reports, 7, 693-703. https://doi.org/10.1016/j.egyr.2021.01.027

Altig, D., Baker, S., Barrero, J. M., Bloom, N., Bunn, P., Chen, S., Davis, S. J., Leather, J., Meyer, B., Mihaylov, E., Mizen, P., Parker, N., Renault, T., Smietanka, P., \& Thwaites, G. (2020). Economic uncertainty before and during the COVID-19 pandemic. Journal of Public Economics, 191, 104274. https://doi.org/10.1016/ j.jpubeco.2020.104274

Ashraf, B. N. (2020). Economic impact of government interventions during the COVID-19 pandemic: International evidence from financial markets. Journal of Behavioral and Experimental Finance, 27, 100371. https://doi.org/10.1016/j.jbef.2020.100371

Baker, S. R., Bloom, N., Davis, S. J., \& Terry, S. J. (2020a). Covid-induced economic uncertainty (No. w26983). National Bureau of Economic Research.

Baker, S. R., Baksy, A., Bloom, N., Davis, S. J., \& Rodden, J. A. (2020b). Elections, political polarization, and economic uncertainty (No. w27961). National Bureau of Economic Research.

Bernard, C., Bondarenko, O., \& Vanduffel, S. (2018). Rearrangement algorithm and maximum entropy. Annals of Operations Research, 261(1-2), 107-134. https://doi.org/10.1007/s10479-017-2612-2

Bhar, R., \& Malliaris, A. G. (2011). Oil prices and the impact of the financial crisis of 2007-2009. Energy Economics, 33(6), 1049-1054. https://doi.org/10.1016/j.eneco.2011.01.016

Bhushan, N., Mohnert, F., Sloot, D., Jans, L., Albers, C., \& Steg, L. (2019). Using a Gaussian graphical model to explore relationships between items and variables in environmental psychology research. Frontiers in Psychology, 10(MAY), 1-12. https://doi.org/10.3389/fpsyg.2019.01050

Brown, R., \& Rocha, A. (2020). Entrepreneurial uncertainty during the Covid-19 crisis: Mapping the temporal dynamics of entrepreneurial finance. Journal of Business Venturing Insights, 14, e00174. https://doi.org/ 10.1016/j.jbvi.2020.e00174

Brown, M. L., \& Kros, J. F. (2003). Data mining and the impact of missing data. Industrial Management and Data Systems, 103(8-9), 611-621. https://doi.org/10.1108/02635570310497657

Cerchiello, P., \& Giudici, P. (2016). Conditional graphical models for systemic risk estimation. Expert Systems with Applications, 43, 165-174. https://doi.org/10.1016/j.eswa.2015.08.047

Choi, S.-Y. (2020). Industry volatility and economic uncertainty due to the COVID-19 pandemic: Evidence from wavelet coherence analysis. Finance Research Letters. https://doi.org/10.1016/j.frl.2020.101783

Dimitriadis, D., \& Katrakilidis, C. (2020). An empirical analysis of the dynamic interactions among ethanol, crude oil and corn prices in the US market. Annals of Operations Research, 294(1), 47-57. https://doi. org/10.1007/s10479-018-2832-0

Epskamp, S., Waldorp, L. J., Mõttus, R., \& Borsboom, D. (2018). The Gaussian graphical model in crosssectional and time-series data. Multivariate Behavioral Research, 53(4), 453-480. https://doi.org/10. 1080/00273171.2018.1454823

Foygel, R., \& Drton, M. (2010). Extended Bayesian information criteria for Gaussian graphical models. Advances in Neural Information Processing Systems 23: 24th Annual Conference on Neural Information Processing Systems 2010, NIPS 2010, pp 1-9.

Friedman, J., Hastie, T., \& Tibshirani, R. (2008). Sparse inverse covariance estimation with the graphical lasso. Biostatistics, 9(3), 432-441. https://doi.org/10.1093/biostatistics/kxm045

Gharib, C., Mefteh-Wali, S., \& Jabeur, S. Ben. (2020). The bubble contagion effect of COVID-19 outbreak: Evidence from crude oil and gold markets. Finance Research Letters. https://doi.org/10.1016/j.frl.2020. 101703

Goodell, J. W. (2020). COVID-19 and finance: Agendas for future research. Finance Research Letters, 35 , 101512. https://doi.org/10.1016/j.frl.2020.101512

Goupillaud, P., Grossmann, A., \& Morlet, J. (1984). Cycle-octave and related transforms in seismic signal analysis. Geoexploration, 23(1), 85-102. https://doi.org/10.1016/0016-7142(84)90025-5

Grinsted, A., Moore, J. C., \& Jevrejeva, S. (2004). Application of the cross wavelet transform and wavelet coherence to geophysical time series. Nonlinear Processes in Geophysics, 11(5/6), 561-566. https://doi. org/10.5194/npg-11-561-2004 
Hailemariam, A., Smyth, R., \& Zhang, X. (2019). Oil prices and economic policy uncertainty: Evidence from a nonparametric panel data model. Energy Economics, 83, 40-51. https://doi.org/10.1016/j.eneco.2019. 06.010

International Monetary Fund. (2020). https://www.imf.org

Khalfaoui, R., Tiwari, A. K., Kablan, S., \& Hammoudeh, S. (2021). Interdependence and lead-lag relationships between the oil price and metal markets: Fresh insights from the wavelet and quantile coherency approaches. Energy Economics, 101, 105421. https://doi.org/10.1016/j.eneco.2021.105421

Khalilpourazari, S., \& Hashemi Doulabi, H. (2021). Designing a hybrid reinforcement learning based algorithm with application in prediction of the COVID-19 pandemic in Quebec. Annals of Operations Research. https://doi.org/10.1007/s10479-020-03871-7

Kılıç, D. K., \& Uğur, Ö. (2018). Multiresolution analysis of S\&P500 time series. Annals of Operations Research, 260(1-2), 197-216. https://doi.org/10.1007/s10479-016-2215-3

Le, T. H., Do, H. X., Nguyen, D. K., \& Sensoy, A. (2020). Covid-19 pandemic and tail-dependency networks of financial assets. Finance Research Letters. https://doi.org/10.1016/j.frl.2020.101800

Liu, Y. A., \& Pan, M.-S. (1997). Mean and volatility spillover effects in the U.S. and pacific-basin stock markets. Multinational Finance Journal, 1(1), 47-62.

Malioutov, D. M., Johnson, J. K., \& Willsky, A. S. (2006). Walk-sums and belief propagation in Gaussian graphical models. Journal of Machine Learning Research, 7, 2031-2064.

Mei-Se, C., Shu-Jung, C. L., \& Chien-Chiang, L. (2018). Time-varying co-movement of the prices of three metals and oil: Evidence from recursive cointegration. Resources Policy, 57(March), 186-195. https:// doi.org/10.1016/j.resourpol.2018.03.003

Mokni, K. (2020). A dynamic quantile regression model for the relationship between oil price and stock markets in oil-importing and oil-exporting countries. Energy, 213, 118639. https://doi.org/10.1016/j. energy.2020.118639

Mokni, K., Hammoudeh, S., Ajmi, A. N., \& Youssef, M. (2020). Does economic policy uncertainty drive the dynamic connectedness between oil price shocks and gold price? Resources Policy, 69(May), 101819. https://doi.org/10.1016/j.resourpol.2020.101819

Oldekop, J. A., Horner, R., Hulme, D., Adhikari, R., Agarwal, B., Alford, M., Bakewell, O., Banks, N., Barrientos, S., Bastia, T., Bebbington, A. J., Das, U., Dimova, R., Duncombe, R., Enns, C., Fielding, D., Foster, C., Foster, T., \& Zhang, Y.-F. (2020). COVID-19 and the case for global development. World Development, 134, 105044. https://doi.org/10.1016/j.worlddev.2020.105044

Rafiq, S., Salim, R., \& Bloch, H. (2009). Impact of crude oil price volatility on economic activities: An empirical investigation in the Thai economy. Resources Policy, 34(3), 121-132. https://doi.org/10.1016/ j.resourpol.2008.09.001

Reboredo, J. C., \& Rivera-Castro, M. A. (2013). A wavelet decomposition approach to crude oil price and exchange rate dependence. Economic Modelling, 32(1), 42-57. https://doi.org/10.1016/j.econmod.2012. 12.028

Reboredo, J. C., \& Rivera-Castro, M. A. (2014). Wavelet-based evidence of the impact of oil prices on stock returns. International Review of Economics and Finance, 29, 145-176. https://doi.org/10.1016/j.iref. 2013.05.014

Salisu, A. A., Ebuh, G. U., \& Usman, N. (2020). Revisiting oil-stock nexus during COVID-19 pandemic: Some preliminary results. International Review of Economics \& Finance, 69, 280-294. https://doi.org/ 10.1016/j.iref.2020.06.023

Shapiro, S. S., \& Wilk, M. B. (1965). An analysis of variance test for normality (complete samples). Biometrika, 52(3/4), 591-611. https://doi.org/10.2307/2333709

Sharif, A., Aloui, C., \& Yarovaya, L. (2020). COVID-19 pandemic, oil prices, stock market, geopolitical risk and policy uncertainty nexus in the US economy: Fresh evidence from the wavelet-based approach. International Review of Financial Analysis, 70(April), 101496. https://doi.org/10.1016/j.irfa.2020.101496

Sui, B., Chang, C.-P., Jang, C.-L., \& Gong, Q. (2021). Analyzing causality between epidemics and oil prices: Role of the stock market. Economic Analysis and Policy, 70, 148-158. https://doi.org/10.1016/j.eap. 2021.02.004

Sun, X., Chen, X., Wang, J., \& Li, J. (2020). Multi-scale interactions between economic policy uncertainty and oil prices in time-frequency domains. North American Journal of Economics and Finance, 51(15), 100854. https://doi.org/10.1016/j.najef.2018.10.002

Tiwari, A. K., Jana, R. K., \& Roubaud, D. (2019). The policy uncertainty and market volatility puzzle: Evidence from wavelet analysis. Finance Research Letters. https://doi.org/10.1016/j.frl.2018.11.016

Tiwari, A. K., Abakah, E. J. A., Le, T.-L., \& Leyva-de la Hiz, D. I. (2021). Markov-switching dependence between artificial intelligence and carbon price: The role of policy uncertainty in the era of the 4th industrial revolution and the effect of COVID-19 pandemic. Technological Forecasting and Social Change, 163, 120434. https://doi.org/10.1016/j.techfore.2020.120434 
Tiwari, A. K., Khalfaoui, R., Solarin, S. A., \& Shahbaz, M. (2018). Analyzing the time-frequency lead-lag relationship between oil and agricultural commodities. Energy Economics, 76, 470-494. https://doi.org/ 10.1016/j.eneco.2018.10.037

Torrence, C., \& Compo, G. P. (1998). A practical guide to wavelet analysis. Bulletin of the American Meteorological Society, 79(1), 61-78. https://doi.org/10.1175/1520-0477(1998)079\%3c0061:APGTWA\%3e2.0. $\mathrm{CO} ; 2$

Tsai, C. L. (2015). How do U.S. stock returns respond differently to oil price shocks pre-crisis, within the financial crisis, and post-crisis? Energy Economics, 50, 47-62. https://doi.org/10.1016/j.eneco.2015. 04.012

Tzagkarakis, G., \& Maurer, F. (2020). An energy-based measure for long-run horizon risk quantification. Annals of Operations Research, 289(2), 363-390. https://doi.org/10.1007/s10479-020-03609-5

Vo, X. V., \& Hung, N. T. (2021). Directional spillover effects and time-frequency nexus between oil, gold and stock markets: Evidence from pre and during COVID-19 outbreak. International Review of Financial Analysis. https://doi.org/10.1016/j.irfa.2021.101730

Wei, Y. (2019). Oil price shocks, economic policy uncertainty and China's trade: A quantitative structural analysis. North American Journal of Economics and Finance, 48, 20-31. https://doi.org/10.1016/j.najef. 2018.08.016

Wen, X., Wei, Y., \& Huang, D. (2012). Measuring contagion between energy market and stock market during financial crisis: A copula approach. Energy Economics, 34(5), 1435-1446. https://doi.org/10.1016/j. eneco.2012.06.021

Williams, D. R., \& Mulder, J. (2020). Bayesian hypothesis testing for Gaussian graphical models: Conditional independence and order constraints. Journal of Mathematical Psychology, 99, 102441. https://doi.org/ 10.1016/j.jmp.2020.102441

World Bank. (2020). World development indicators (WDI) database. https://databank.worldbank.org

World Health Organization. (2020). https://www.who.int

Wu, W., Tiwari, A. K., Gozgor, G., \& Leping, H. (2021). Does economic policy uncertainty affect cryptocurrency markets? Evidence from Twitter-based uncertainty measures. Research in International Business and Finance, 58, 101478. https://doi.org/10.1016/j.ribaf.2021.101478

Yaya, O. O. S., Tumala, M. M., \& Udomboso, C. G. (2016). Volatility persistence and returns spillovers between oil and gold prices: Analysis before and after the global financial crisis. Resources Policy, 49, 273-281. https://doi.org/10.1016/j.resourpol.2016.06.008

Yousfi, M., Ben Zaied, Y., Ben Cheikh, N., Ben Lahouel, B., \& Bouzgarrou, H. (2021). Effects of the COVID19 pandemic on the US stock market and uncertainty: A comparative assessment between the first and second waves. Technological Forecasting and Social Change, 167, 120710. https://doi.org/10.1016/j. techfore.2021.120710

Zhang, W., \& Hamori, S. (2021). Crude oil market and stock markets during the COVID-19 pandemic: Evidence from the US, Japan, and Germany. International Review of Financial Analysis, 74, 101702. https://doi.org/10.1016/j.irfa.2021.101702

Zhang, X., Yu, L., Wang, S., \& Lai, K. K. (2009). Estimating the impact of extreme events on crude oil price: An EMD-based event analysis method. Energy Economics, 31(5), 768-778. https://doi.org/10.1016/j. eneco.2009.04.003

Zhang, Y. J., \& Yan, X. X. (2020). The impact of US economic policy uncertainty on WTI crude oil returns in different time and frequency domains. International Review of Economics and Finance, 69(April), 750-768. https://doi.org/10.1016/j.iref.2020.04.001

Publisher's Note Springer Nature remains neutral with regard to jurisdictional claims in published maps and institutional affiliations. 